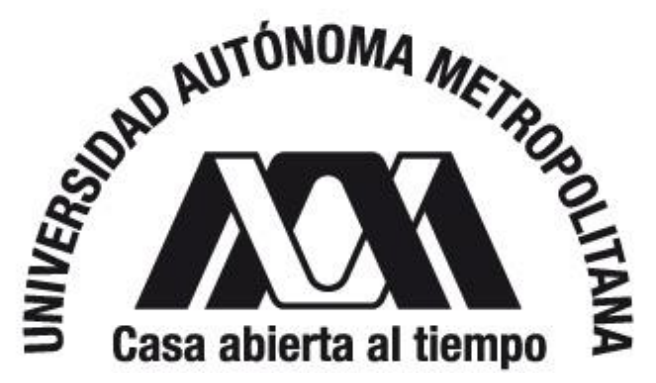

\author{
Unidad Iztapalapa \\ División de Ciencias Sociales y Humanidades \\ Departamento de Filosofía
}

Coordinación de Lingüística

\title{
Las escrituras del spanglish en el siglo XXI
}

\author{
Idónea Comunicación de Resultados \\ que para obtener el grado de maestra en humanidades \\ (Línea Lingüística) \\ presenta \\ Jessica del Carmen Contreras Méndez
}

Asesora: Dra. Laura A. Hernández Martínez

Ciudad de México, diciembre de 2018 


\section{Agradecimientos}

Esta tesis se escribe en plural no porque busque llegar al punto de ya no decir yo, sino a aquél en el que decirlo o no decirlo no tenga importancia. Aquí escriben muchas voces. No olvidamos todos los nombres detrás de los cuestionamientos, las lecturas, las horas de escucha y las intervenciones. En esta página queremos mencionar algunos nombres detrás de las palabras que presentamos.

Los agradecimientos más profundos para Laura Hernández, por su paciencia, por sus múltiples enseñanzas y contra-aprendizajes, por todas las horas dedicadas a la creación de este trabajo que sin ella, en ningún sentido, hubiera sido posible. Gracias por trazar conmigo ese camino de pensamiento siempre constante, por el enriquecimiento personal, las anécdotas, las miles de referencias, por el interés en cuestionar-me y por el apoyo en la búsqueda de una lingüística-menor, una contralingüística.

Gracias también a Juan Cuamba: el azar se encargó de retornarme, diferente, a ese punto de la literatura que se presentaba ya en nuestros primeros encuentros. Gracias por seguir trazando multiplicidades a partir de la conjunción de nuestras vidas, por las miles de palabras intercambiadas en todos los medios posibles, por el constante devenir y la crítica continua. Que nuestras palabras queden siempre dispuestas a encontrarse en el jardín de los senderos que se multiplican.

A Slovenia Martínez y a Julio Serrano, gracias por la lectura y por todos los comentarios que ayudaron a la articulación de este trabajo. En el mismo sentido, extiendo un agradecimiento a todos los profesores de la línea en lingüística dentro del posgrado en humanidades, por sus comentarios en los seminarios de investigación pero también por compartir sus conocimientos en las clases.

Igualmente, gracias profundas a mis padres, hermanos miles, sobrina múltiple, amigos: a Graciela, Juan Alberto, Yunuén, Nubia, Aymara, Irma, Benjamín, Osvaldo, Fernanda y Fabiola. Sin sus lenguajes, sin el eco de sus palabras siempre sorprendente, ninguna idea se hubiera gestado; gracias por hablar.

Agradecemos también a todas aquellas presencias que han bordado parte de este cuadro con sus constantes interlocuciones, con todas sus recomendaciones bibliográficas, su interés y sus preguntas: a Pablo Leal, Mónica Contreras, María Contreras, María Lerma, Manuel de la Cruz, Fernando Ochoa, Alberto Cortés, Leonora Xánath, y Eréndira Ornelas. Gracias también a mis compañeros del posgrado, Dulce Coronel, Claudia Sánchez. Tania Campaña, Rocío Hernández, Enrique Espejel, Ángeles Rodríguez, Jorge Morales y Yúrik García, por el enriquecimiento en este proceso. Igualmente, gracias a Juan Manuel García por todo el apoyo 
Gracias infinitas a Gibrán Mubarqui por los muchos caminos en los que hemos tropezado juntos, por la creación de nuevos lenguajes, por lanzarle bombas a las palabras y a todos los significados establecidos. Gracias por todos los afectos y afectaciones, por el devenir-animal y por la constante interlocución.

En el primer final de unas palabras, comienzan todas las otras: gracias a Manuel Lunari, por cada letra y por todos los libros, a Elizabeth Castro, porque every written word is political, y a Brenda Nava, por todas las palabras habladas.

Asimismo, gracias a las personas detrás de Vulvxtrix por la no-filosofía, el no-feminismo, la notecnología y la otra teoría posible. Nuestros diálogos resuenan en estas páginas.

Finalmente, agradezco al Posgrado en Humanidades de la Universidad Autónoma Metropolitana, unidad Iztapalapa, y al Consejo Nacional de Ciencia y Tecnología (CONACyT), por el apoyo brindado para la realización de esta investigación. 


\section{Índice}

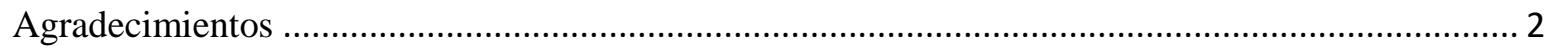

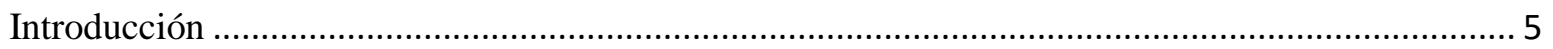

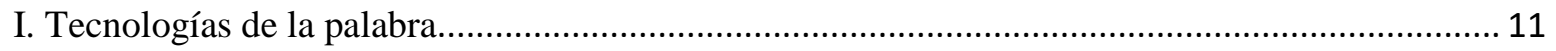

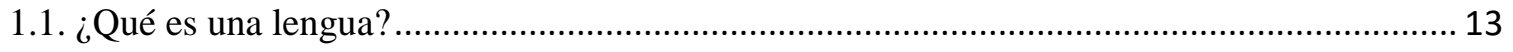

1.2. Tecnologizar la palabra: de la oralidad a la escritura ......................................................... 18

1.3. Lingüística de la escritura ......................................................................................... 22

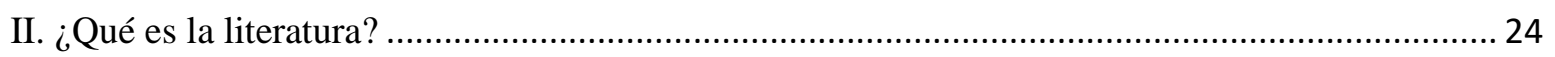

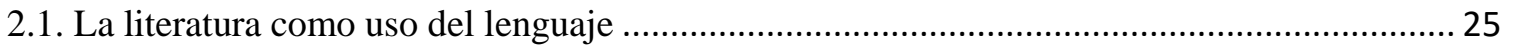

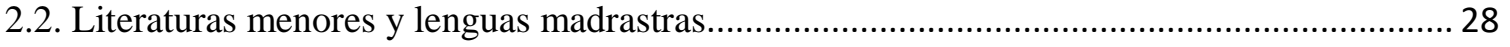

2.3. Hacia un análisis discursivo de la literatura en spanglish ..................................................... 34

III. Te llamo pa'trás: manifestaciones del spanglish en las escrituras latinas ................................ 41

3.1. Hablar desde donde se habla: escritura en la liminalidad................................................. 42

3.1.1. Los chicanos de Aztlán: si nos construyen muros, se los tiramos con palabras .............. 44

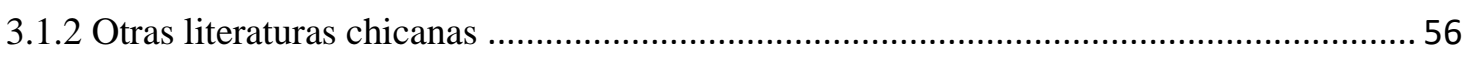

3.2. Hablar de lo que habla: ¿es posible un metaspanglish? ................................................... 58

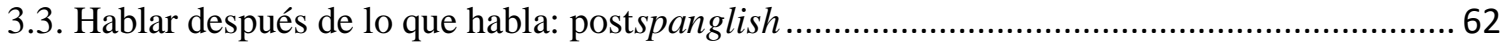

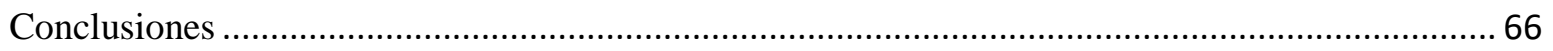

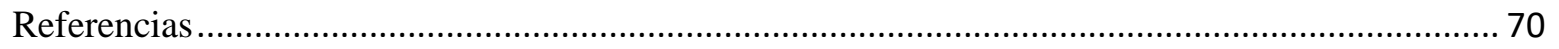

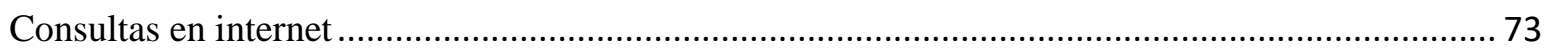

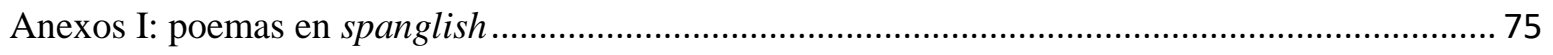

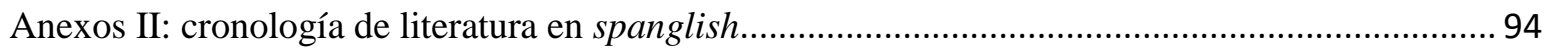




\section{Introducción}

"El arte nunca será suficiente"

Translation:

Art is just a pretext for... for... for...

(grito)

Robo-esperanto \#1, Guillermo Gómez-Peña

En la década de 1960, después de varias olas de migración entre Estados Unidos y México (primero del norte al sur, luego del sur al norte) y de cambios geopolíticos en la conformación de la frontera norte de México (la frontera sur de Estados Unidos), surgió un movimiento social por los derechos civiles llamado Movimiento Chicano. Inicialmente, los chicanos buscaban mejorar sus condiciones de vida tanto dentro de sus trabajos como fuera de estos, en las escuelas, en los espacios que habitaban. Por los mimos años, desde 1965, un gran número de cubanos comenzó a migrar hacia Estados Unidos; se dio también el primer éxodo de puertorriqueños y más tarde, entre 1970 y 1980, comenzó también una gran ola de migración salvadoreña hacia territorio estadounidense. Un gran porcentaje de los primeros tres grupos participaron en programas de educación bilingüe, y llegaron a conformar las poblaciones hispanohablantes más numerosas fuera de sus países de origen (Stavans 1999, 159). Actualmente, más de cincuenta millones de personas hablan español en Estados Unidos (Rivera 2018).

Dentro del Movimiento Chicano, la gráfica y la literatura ocuparon un lugar primordial en la difusión de mensajes políticos, en la creación de una conciencia chicana y en la conformación de una comunidad que cruzara las fronteras políticas, raciales y étnicas. Así, los chicanos buscaban también crear lazos con las luchas de otros grupos dentro de Estados Unidos: con la comunidad afroamericana, con la comunidad tailandesa, con todas las comunidades latinas (cubana, puertorriqueña, salvadoreña, hondureña) que también se encontraban a diario con la migración, la segregación, el racismo, con otra nueva 
colonización y con otras formas de opresión. Una de las particularidades de las comunidades latinas era la relación que trazaban con el espacio geográfico, por la cercanía con sus países de origen. Sin embargo, a diferencia de otros grupos latinos, muchos chicanos no habían migrado hacia Estados Unidos, sino que habían habitado ese territorio por décadas, desde antes de que México perdiera parte de su territorio con los Tratados de Guadalupe Hidalgo. Esas comunidades habitantes del territorio habían sido hispanohablantes, para convertirse luego en angloparlantes cuando se les impuso el inglés como lengua, aunque inmediatamente después de la guerra se había declarado que el territorio al norte del Río Bravo sería bilingüe (lo que, por otra parte, nunca se cumplió).

Así, ocurrió lo que en muchas otras fronteras y en muchos otros países (colonizados y no): las dos lenguas, las de los dos territorios, entraron en contacto, generando primero nuevas formas de expresión oral que pasaron luego a la escritura. Primero en carteles, letreros, grafitis y murales, luego a la literatura: el espanglish ${ }^{l}$, esa conjunción entre el inglés y el español, ya no aparecía sólo en la oralidad sino que tomaba un sistema de escritura para darle una forma visual a las palabras. Pero hablar español era motivo de castigo: en las escuelas, los alumnos que lo hablaban eran castigados, en la calle eran perseguidos.

El spanglish aparecía en la creación literaria chicana como un mecanismo para poner al frente la problemática sobre la manera en que las comunidades mexicoamericanas vivían al norte de la frontera mexicana, muchas veces sin acceso a la educación, sin poder hablar su lengua en territorio estadounidense (cuando el español estaba prohibido), perteneciendo a una nación con la que no compartían muchos aspectos culturales, anhelando el pasado y la historia de un país que muchos no conocieron ${ }^{2}$. También en este sentido, la palabra spanglish

\footnotetext{
${ }^{1}$ Desde su aparición a mediados del siglo XX, según el registro de Ngram en Google (consultado en 2018), la palabra 'spanglish' ha sido utilizada para hablar de la conjunción entre el inglés y el español, y puede encontrarse escrita de dos maneras: "spanglish" y "espanglish". Esta ambigüedad se aproxima al problema de la presencia de una de las dos lenguas en la gramática de la otra (¿qué estructuras gramaticales se retoman de qué lengua en un enunciado específico?), por lo que en el presente ensayo se retomarán ambas escrituras como una manera de marcar la diferencia entre aquellos textos en los que los autores escriban en inglés, aquellos en los que escriban en español, y en los que lo hagan en ambas lenguas. Así, por ejemplo, parece más adecuado hablar de 'espanglish', con un $e$ epentética que haga referencia a la presencia del español, para hablar de las escrituras de Gloria Anzaldúa, mientras que ‘spanglish' parece más adecuado para hablar de las escrituras de Denice Frohman o Melissa Lozada-Oliva, quienes escriben en inglés. Para aquellos casos en los que se hable de la presencia de las dos lenguas (sin hacer referencia a la presencia de alguna en mayor medida) o en los que se hable de la cultura, se retomará la escritura 'spanglish'.

${ }^{2}$ De esta manera, el espanglish y la literatura chicana, en el siglo pasado, hacían énfasis en la problemática sobre lo que Gloria Anzaldúa llamó la nueva identidad mestiza (the new mestiza).
} 
comenzó a utilizarse para hablar de la manera en que muchos latinos, migrantes o no, viven a diario en Estados Unidos. En ese contexto, ¿qué implicaba seguir hablando español? ¿Qué significaba escribirlo, cuál era el peso de utilizarlo junto al inglés, en un mismo enunciado? Gustavo Pérez Firmat, poeta cubano, escribió Dedication ${ }^{3}$, en inglés, para hablar de ese sentimiento:

The fact that I
am writing to you
in English
already falsifies what I
wanted to tell you.
My subject:
how to explain to you
that I don't belong to English
though I belong nowhere else,
if not here
in English.

Los escritores latinos en Estados Unidos, dice Ilan Stavans (1999), habitan el abismo lingüístico de tener dos lenguas, una como natal y otra como adoptada (sic). Las primeras generaciones de migrantes mantenían el español como lengua de resistencia frente a la prohibición de hablarla, mientras que las generaciones posteriores comenzaron a aceptar el uso del inglés, que se les presentaba como ventajoso. A veces hay que elegir entre aprender la lengua del amo, del capital y de las máquinas, y perder la propia lengua, decía Derrida (1997). Sin embargo, esto no ocurrió así en las comunidades latinas, pues siguieron hablando español para mantener su historia: los cubanos exigieron programas de educación bilingüe para no perder su lengua materna, pues muchos pensaban regresar a la isla (Stavans 1999, 161). Así, a finales de la década de 1990 existían cuatro grupos hispanohablantes en Estados Unidos: los chicanos, puertorriqueños, cubanos y otros (entre los que se encontraban venezolanos y salvadoreños, grupos que ahora son más numerosos que el de los cubanos).

\footnotetext{
${ }^{3}$ Stavans (1999) presenta una traducción de este poema, aunque fue publicado originalmente en Bilingual Blues (compilación de poemas de 1980-1994).
} 
Las escrituras latinas en Estados Unidos no aparecen solamente en español, sino también en spanglish, en esa conjunción de lenguas que inicialmente aparecía sólo de manera oral y que comenzó a escribirse en anuncios publicitarios, en redes sociales, en carteles y en otros medios. El spanglish llegó a la escritura y también a la literatura.

Escribir una lengua ha establecido relaciones distintas con la lengua oral. Inicialmente, podríamos pensar que la lengua escrita fija ciertos usos de la lengua oral, y podríamos también pensar en el papel que ha jugado la escritura en la conformación de las lenguas nacionales. Sin embargo, las lenguas no se acercan a la escritura solamente en un sentido. Tanto se valen de las grafías para la comunicación, para mantener mensajes en el tiempo, como la utilizan para la conservación de la memoria y para la creación literaria. Es este último uso uno de los que se ha ligado en mayor medida a la fijación de las lenguas nacionales, pues se asume que sólo en estas lenguas reconocidas es que la lengua se acerca a la escritura literaria. En este sentido, ¿cómo llega a la escritura un lenguaje no reconocido, qué puede decirse en él, qué tipo de literatura permite? Cuando los lenguajes que no responden a la gramática de una lengua mayor se acercan a la escritura, particularmente a la escritura literaria, ¿de qué manera lo hacen?

Partiendo de lo anterior, planteamos que el spanglish crea distintas formas de acercarse a la lengua escrita, particularmente en la literatura. En dichas producciones literarias, los escritores en spanglish participan de escenas enunciativas específicas desde las cuales producen enunciados concretos, cargados con palabras que permiten trazar otras relaciones entre ellos, su posición como sujetos históricos en la escena enunciativa, la lengua y la cultura.

Al suponer que son ciertas lenguas mayores las que acceden a la literatura (como campo de homogeneización de la lengua, de reconocimiento), resulta importante ver la posición que tiene el spanglish en este campo. En el sentido en que una lengua se toma como tal a partir de que tiene literatura, se podría plantear que la literatura en spanglish es una forma de universalizarlo, de darle estatus y de generar un campo para convenciones sobre su escritura, aunque, en la dirección contraria, también podría tomarse la creación linguiística escrita en spanglish como no necesariamente literaria, si se ve a la literatura como un campo de escritura en lenguas mayores. 
Distintas editoriales, como Ediciones del Norte, Aunt Lute Books ${ }^{4}$, Third Woman Press $^{5}$, Arte Público Press ${ }^{6}$ y Mondadori ${ }^{7}$, entre otras, han publicado títulos de escritores latinos en spanglish (como Junot Díaz, Sandra Cisneros y Giannina Braschi), aunque cada una tiene un público y un alcance distinto en el mercado. Por tanto, pensar que no son sólo editoriales latinas independientes las que publican en spanglish, supone que éste se mueve de diferentes maneras entre los lectores en mercados más amplios (como el de Mondadori). En este sentido, la traducción de Don Quixote de La Mancha que realizó Ilan Stavans, permite cuestionar si el spanglish puede ser considerado como lengua o no, si la literatura en spanglish cuenta como tal, quiénes son los que escriben en spanglish, de qué manera lo hacen, etcétera ${ }^{8}$. En el caso de Junot Díaz, sucede que sus obras, aun siendo escritas en spanglish permiten la traducción desde el inglés hacia el español, es decir, de un spanglish que participa de las estructuras gramaticales del inglés hacia uno que participa de las del español. En este sentido, también retomar obras escritas cuya temática sea el uso mismo del spanglish, permite postular la existencia de una consciencia sobre este lenguaje de los propios escritores, puesto que lo utilizan de forma oral y además escriben al respecto.

Para plantear lo anterior, partimos de la Idónea Comunicación de Resultados, El espanglish como lenguaje liminal, en la que se analizaron ciertas estructuras del spanglish, mayores al léxico, para confrontarlas con las analizadas por L. F. Lara en Para la historia lingüística del pachuco (1992), donde el autor analizaba el spanglish a partir de la manera en que ciertas palabras se tomaban desde el inglés para adaptarse en el español de los pachucos, sobre todo desde la fonética y la morfología. Para la conformación del corpus analizado en dicho trabajo, se tomaron anuncios publicitarios y publicaciones en redes sociales, lo que permitió ver que el spanglish no aparecía solamente en la oralidad sino que también se acercaba a distintos tipos de escritura. En este sentido, ver las portadas de los libros escritos

\footnotetext{
${ }^{4}$ Editorial que publica la obra de mujeres cisgénero y transgénero, sobre todo de mujeres lesbianas y mujeres de color, desde 1982.

${ }^{5}$ Third Woman Press es una editorial que, desde 1979, publica la obra de feministas queer y de color.

${ }^{6}$ Arte Público Press es la editorial de literatura escrita por autores latinos más grande de Estados Unidos

${ }^{7}$ Random House Mondadori fue una de las editoriales más grandes, originaria de Italia, en conjunto con Penguin Random House.

${ }^{8}$ Tratar de analizar estas cuestiones no será un objetivo de la investigación, como sí lo será analizar de qué manera las traducciones de una obra en spanglish pueden realizarse hacia alguna de las lenguas que lo conforman, en el sentido en que esto último resulta relevante para pensar cómo aparece una u otra lengua dentro de una obra determinada.
} 
por autores latinos, en las que se conjugaban el inglés y el español, y conocer dichas obras, permitió pensar en las maneras distintas en las que el spanglish se acercaba a la escritura y en las formas en que era presentado, como lenguaje de una comunidad latina, en una sociedad angloparlante.

Respecto a esto último, vale la pena retomar el concepto de 'paisaje linguiístico' (linguistic landscape), propuesto por R. Landry y R. Bourhis en Linguistic Landscape and Ethnolinguistic Vitaliy: An Empirical Study (1997) para hablar del paisaje conformado por el lenguaje de todos los signos gráficos en un territorio determinado. Este tema se ha estudiado en comunidades diversas donde conviven dos lenguas o más, y permite conocer el estadio en el que se encuentra una comunidad lingüística a través de la escritura ${ }^{9}$. Así, pensar los paisajes lingüísticos en las comunidades latinas es relevante para conocer las maneras en que se conjugan el inglés y el español en ciertos espacios públicos donde aparecen, porque esto sería un signo de que se reconoce la existencia de una comunidad hablante de ambas lenguas, a la que se dirigen dichos mensajes. En este sentido puede hablarse de una connotación política en aquellos signos gráficos donde aparecen ambas lenguas, pues implican la existencia de un grupo que crea dichos anuncios (hablantes de ambas lenguas o no, empresas chicas, mayores, públicas o privadas, etcétera) y un grupo que los lee. Esto también permite trazar relaciones entre la cultura, la posición de un grupo lingüístico y la concepción de éste dentro de un espacio ${ }^{10}$.

El presente ensayo tratará de esbozar algunas de estas cuestiones en torno al uso del lenguaje en la literatura en spanglish, pensando en ese entramado de nexos entre la escritura

\footnotetext{
${ }^{9}$ Por ejemplo, cómo distintas comunidades de migrantes manifiestan su lengua en carteles y otros signos, tema que presenta Yujing Ma (2017) en su trabajo sobre el paisaje lingüístico chino-español en la ciudad de Valencia, permite conocer en qué grado una comunidad de habla conformada por migrantes se ha integrado a la comunidad a la que ha migrado. Así mismo, el trabajo de Franco Rodríguez (2007) sobre el paisaje lingüístico en el condado de Miami-Dade se centra en el contacto entre inglés y español que se da en este territorio de Florida. En este ensayo, el autor también trata de dar una explicación lingüística a los errores gramaticales que encuentra en los signos que documenta, en tanto que son producidos por hablantes de español cuya segunda lengua es el inglés.

${ }^{10}$ Aunque este tema no se analizará aquí, es importante aclarar que sí se retomará la discusión en un último apartado, para hablar sobre la postura política de las escrituras literarias en spanglish, distinta a aquella con la que se producen signos gráficos en el espacio público.
} 
como soporte, como medio y como uso del lenguaje, en su relación con la cultura, con lo político y con la representación de un grupo dentro del ámbito literario ${ }^{11}$.

De tal manera, en un primer apartado hablaremos de la manera en que la lingüística ha abordado a la escritura como otra materialidad del lenguaje oral ${ }^{12}$, en relación con el cambio lingüístico y con el reconocimiento de las lenguas. En un segundo apartado trataremos la relación entre el lenguaje y la literatura, en el sentido en que la literatura es un uso del lenguaje, por un lado, pero también en el sentido en que la literatura se relaciona con las lenguas nacionales y con los usos del lenguaje alejados del estándar, por lo que constituye un uso político del lenguaje. Posteriormente, expondremos de qué manera es posible estudiar la literatura en spanglish en tanto discurso, para lo que se retomará el trabajo de cuatro autores, M. Bajtín, E. Benveniste, P. Bourdieu y M. Foucault. En un cuarto apartado se hablará brevemente sobre cómo el spanglish ha aparecido en la literatura, desde el movimiento chicano hasta las escrituras latinas del presente siglo, para analizarlas tomando en cuenta las nociones sobre el discurso, el lenguaje y la literatura, planteadas anteriormente.

Para lo anterior, se analizará un corpus histórico compuesto por enunciados extraídos de obras literarias, poéticas, de escritores chicanos como Gloria Anzaldúa, Alurista y Guillermo Gómez-Peña, para pasar luego a la poesía de Yosimar Reyes, Denice Forhman y Melissa Lozada-Oliva, quienes escriben en el presente siglo.

\section{Tecnologías de la palabra}

El uso de la lengua implica la puesta en marcha de un aparato: el cuerpo, en el caso de las lenguas orales y las lenguas de señas (el aparato fonador, las manos, los brazos, la cara); el cuerpo más un instrumento (como prótesis a las manos, a los brazos), en el caso de las lenguas escritas. Así aparece la lengua en su forma sonora, visual, gráfica. La escritura entonces

\footnotetext{
${ }^{11}$ En este último sentido, se hablará de escrituras, en plural, rescatando nuevamente la heterogeneidad de relaciones que cada escritor plantea con su escritura y con la lengua en la que enuncia aquello que escribe.

${ }^{12}$ Respecto a esto, Julia Kristeva menciona en El lenguaje, ese desconocido: introducción a la lingüística (1988) que la escritura es una de las tres formas de la materialidad del lenguaje, junto con el gesto y el sonido: la materialidad es lo que permite que haya lenguaje.
} 
permite fijar la palabra que, en su naturaleza oral, resultaba evanescente ${ }^{13}$ : aunque las palabras escritas no se vuelven eternas, ya no resultan efímeras como las palabras orales, "la escritura las encierra tiránicamente para siempre en un campo visual" (Ong 1987, 21). A partir de esta permanencia en el tiempo y el espacio, la escritura de las lenguas puede también moverse entre puntos geográficos distantes, y puede disponer palabras sobre el espacio de los distintos soportes donde sean plasmadas.

La escritura presupone la existencia de un sistema oral al cual dar una forma gráfica: para J. Ong $(1987,18)$, puede existir oralidad sin escritura pero nunca escritura sin oralidad. Sin embargo, esta relación pueden ser discutida: ¿es la escritura un sistema de modelado de la lengua oral? De ser así, ¿cómo la lingüística se ha acercado a la escritura de las lenguas, si ha pensado en las lenguas orales como su único objeto de estudio? En este último sentido, F. de Saussure $(1945,52)$ hablaba sobre la necesidad de la escritura de las lenguas para el estudio lingüístico de éstas: ¿es ese el único acercamiento desde la lingüística hacia la escritura?

Quizá una de las diferencias primordiales entre las lenguas escritas y las lenguas orales sea la manera en que ambas son adquiridas por los grupos que las utilizan: el acercamiento a la escritura de una lengua siempre se encontrará determinado por factores como las políticas del lenguaje y el acceso a la educación, mientras que la adquisición de una lengua oral estará disponible para cualquier persona que entre en contacto con ella. Desde aquí podemos ya presuponer que la escritura de una lengua es un fenómeno mucho más complejo que el de buscar y utilizar signos gráficos para palabras orales.

En el sentido anterior, es necesario también ahondar en la relación de la escritura con la literatura. Retomando aquella idea de una lingüística que estudia exclusivamente las lenguas orales (aunque las estudie a partir de la escritura), la escritura permite uno de los elementos que, para autores como Saussure son requisito para considerar a una lengua como tal: la literatura $(1945,221)$. Siguiendo este camino, algunos dialectos podrían ser clasificados, en realidad, como lenguas, en tanto que existe literatura escrita en ellos (aunque

\footnotetext{
${ }^{13}$ Quizá aquí valdría la pena pensar en qué sentidos y hasta qué límites puede ser suspendida esa evanescencia de la palabra, cuando la escritura también puede valerse de soportes como el aire o el agua, aunque cabe resaltar también que, aún en estos medios relativamente efímeros, la palabra perdura en el tiempo más que en su soporte sonoro.
} 
sin olvidar que la literatura fue inicialmente oral, y que existe aún en lenguas sin sistemas de escritura). Es aquí donde debe retomarse la discusión sobre el concepto de lengua, para entender el papel que la escritura y la literatura juegan en su definición.

Así, en el presente apartado retomaremos la discusión en torno a las lenguas orales ${ }^{14}$ frente a las lenguas escritas siguiendo el siguiente camino: primero, hablaremos sobre la definición de lengua oral, sus límites y las maneras en que distintas áreas de la lingüística la han abordado (pues aquí aparece la relación literatura-escritura-oralidad) para poder después discutir sobre la escritura y sus implicaciones, en relación con el sistema lingüístico, la sociedad y la cultura. Estos dos puntos nos permitirán hablar sobre cómo se ha abordado el asunto de la escritura desde la lingüística, en un tercer punto.

\section{1. ¿Qué es una lengua?}

En el Curso de lingüística general, F. de Saussure definía 'lengua' tomando al sonido como una de sus características principales: la lengua era oral, y la escritura funcionaba como una forma de representar ese sistema sonoro $(1945,51)$. Así, la lengua oral fue objeto de estudio de la lingüística, dejando de lado cualquier sistema escrito (en algún punto, Saussure deja de hacer la distinción entre 'lengua oral' y 'lengua escrita' para utilizar sólo 'lengua' y 'escritura', respectivamente) aunque aceptara que la escritura era necesaria para la producción y difusión de conocimiento, pero también para poder estudiar lenguas muertas cuyo único registro se encontraba en la escritura. La lingüística, entonces, no se acerca a la escritura para estudiarla: en tanto que representa a la lengua oral, la escritura le permite un acercamiento a los sistemas lingüísticos y a sus cambios.

Saussure propone que la etnología, las relaciones entre las lenguas y las instituciones, entre la historia de una lengua y la de una civilización, entre lengua e historia política y la

\footnotetext{
${ }^{14} \mathrm{Al}$ hacer referencia a las lenguas orales no olvidamos la existencia de las lenguas de señas ni negamos su importancia o las delegamos a un segundo lugar; retomamos más bien aquella primera distinción presentada por Saussure sobre el objeto de estudio de la lingüística para esta discusión, pero también pensamos que las lenguas de señas aparecen cuando la lengua oral no es posible.
} 
relación entre la extensión geográfica de las lenguas y su fraccionamiento dialectal formen parte de lo que él llama lingüística externa $(1945,48)$, que se encargaría de todo aquello que no forma parte del sistema interno de la lengua, el único tema que interesa a la lingüística (Bourdieu 2008, 6). En este sentido, la sociolingüística sería una disciplina (de la linguiística externa) que intentará mostrar el comportamiento de la lengua como sistema inmerso en un contexto social específico (Rotaexe 1990, 15), por lo que retoma su heterogeneidad social, considera a la lengua como un elemento importante para la organización colectiva (de ahí su importancia política en ciertas comunidades) y no olvida que su uso depende de decisiones ligadas a las instituciones de la sociedad que la habla.

La sociolingüística se interesará por los elementos políticos de la sociedad, en tanto que permiten la variación del sistema interno de la lengua, es decir, por las relaciones entre el ámbito social de los hablantes y la lengua que utilizan para comunicarse Sin embargo, explorar otros aspectos respecto a la relación entre el ámbito de lo político y el lenguaje no será su objeto de estudio. Esta disciplina no considera que a las lenguas como homogéneas, sino que se interesa por la variación que puede existir entre los distintos usos de la lengua (y los plantea como dialectos o variedad de ese sistema que, sin embargo, sí se constituye como homogéneo en tanto que participa de reglas sintácticas, fonológicas, morfológicas, etcétera).

Pese a lo anterior, para Saussure es necesario pensar en las relaciones que traza la lengua con elementos externos a su sistema gramatical, como mencionábamos antes, pues la lengua “es la que en gran medida hace a la nación” (Saussure 1945, 44). En este sentido, será para él un símbolo nacional como la literatura, que se constituye como uno de los elementos distintivos de las lenguas frente a los dialectos (las lenguas tienen literatura, mientras que los dialectos no). Aquí nos gustaría introducir la relación, que se mueve en varias direcciones, entre el concepto de lengua y el de estado-nación: si bien en la historia de una lengua pueden ubicarse distintos momentos desde que ésta es clasificada como un dialecto distinto de alguna variedad lingüística hasta que se conforma como una lengua (de manera que esta distinción se plantea como un continuum ${ }^{15}$ ), el hecho de que una lengua aparezca dentro de un territorio

\footnotetext{
${ }^{15}$ Desde la sociolingüística, este continuum plantea siete estadios de lengua según cuatro criterios: vitalidad, autonomía, historicidad y normatividad. Según estos criterios, una variedad lingüística puede ser la norma, puede ser una variedad clásica, artificial, vernácula, un dialecto, una lengua criolla o un pidgin, dejando a los argots, jergas y lenguas secretas como subvariedades de una lengua. (Rotaexe 1990). En este punto resulta útil
} 
geográfico, delimitado, perteneciente a una nación que toma a esa lengua como suya, será un aspecto importante en esa definición (Bourdieu 2008, 22).

Al respecto J. Derrida, en El monolingüismo del otro o la prótesis de origen (1997), habla de procesos de colonización o criollización en los que la lengua que el conquistador toma como suya es impuesta al pueblo colonizado, que no reconocerá esa lengua como propia aunque la adquiera. De tal suerte, la distinción entre lengua, dialecto o idioma queda suspendida para él, pues esos fenómenos por los cuales un dialecto o una lengua son reconocidos como tales son aquellos que atraviesan las fronteras de las distinciones entre sistemas lingüísticos (y que quedarían en el campo externo de la lingüística para Saussure). Para Derrida, pues, no existe un idioma puro en el sentido en que dentro de cualquier sistema lingüístico se ve impresa la huella de los procesos de capitalización de una lengua sobre otra. Nunca se habla, pues, una sola lengua, aunque quien la hable utilice "únicamente" el sistema de esa lengua: las lenguas impuestas son lenguas extranjeras siempre. Desde ahí cabe también pensar en aquellos discursos que permiten al colono decir que una lengua es suya, es decir: si la lengua no es una propiedad, lo que lleva a alguien a decir que una lengua le pertenece son las condiciones discursivas bajo las cuales esta afirmación puede plantearse como un acto de habla (y resultar exitoso).

Aquí es donde reflexionar acerca de las distinciones que hace la lingüística entre lengua y dialecto desde un punto de vista político es necesario: si bien la gramática (como las reglas del sistema de la lengua, lo que constituye a la lengua), es una condición necesaria, en tanto homogénea y estable (Saussure 1945, 39-43), para distinguir dialectos, nos encontramos con que esto no funciona así para aquellos que, aún con reglas gramaticales, no son considerados como lenguas en tanto que no establecen la relación que éstas tienen con el estado-nación. Las lenguas, pues, son un estadio de mayor prestigio frente a los dialectos,

retomar a G. Deleuze (2008), quien recupera de Gobard una clasificación que busca dejar de pensar a las lenguas en términos binarios: "el dualismo o el binarismo corren el peligro de dejarnos en una oposición simple entre lengua culta y lengua vulgar, entre lengua mayor y lengua menor, o bien entre una lengua de poder y una lengua del pueblo. Los cuatro factores de Gobard, al contrario, no sólo complementan a los anteriores sino que nos proponen para ellos una génesis compleja. ¿Cómo se hace una lengua con el poder? ¿Cómo conjurar el poder lingüístico?" (Deleuze 2008, 77). La propuesta de Gobard, frente a la anterior, permite pensar en una clasificación lingüística que tome en cuenta los movimientos de las lenguas mismas en su uso, en su realidad y no en su potencia. 
dentro del territorio geográfico que se corresponde con el de un estado-nación. Es ahí también donde entra el asunto que nos compete en el presente trabajo: el spanglish, que ha sido designado como un dialecto del español (o del inglés, según el caso) pese a presentar ciertas reglas gramaticales ${ }^{16}$.

Para F. de Saussure, como mencionamos, otra de las distinciones entre una lengua y un dialecto es la creación literaria existente en las primeras, y no en los segundos. Sin embargo, volvemos a encontrarnos con "dialectos" que, a partir de su acercamiento a la escritura, han llegado a la literatura (este es el caso también del spanglish, que ha aparecido en la literatura desde el movimiento chicano pese a que sigue sin ser considerado como lengua).

Las categorías linguiísticas, entonces, responden a factores de orden político externos a la lengua, desde donde esta distinción se plantea como necesaria en tanto que legitima la posición de unas lenguas frente a otras. Desde aquí, estudiar lenguas sin esa homogeneidad gramatical, sin procesos de gramaticalización, sin gramática ${ }^{17}$, según los modelos lingüísticos (pensados para las lenguas legítimas, como las llama P. Bourdieu), implica dejar de lado las estructuras de poder que atraviesan a las lenguas: “el modelo lingüístico por el que la lengua deviene objeto de estudio se confunde con el modelo político por el que la lengua está de por sí homogeneizada, centralizada, estandarizada, lengua de poder, mayor o dominante" (Deleuze y Guattari 2002, 103).

En este sentido político de las clasificaciones lingüísticas, nos gustaría retomar las palabras de Yásnaya Aguilar quien, en un sentido parecido a aquel en el que Max Weinrich decía que las lenguas eran dialectos con ejército y marina, dice que las lenguas indígenas son aquellas que, a diferencia de otras, se las arreglan para sobrevivir sin Estado que las respalde (cit. por Rivera, 2018). Regresamos entonces a la necesidad de pensar las clasificaciones

\footnotetext{
${ }^{16}$ Esta discusión formó parte del trabajo El espanglish como lenguaje liminal presentado para obtener el grado de licenciada en lingüística. En este trabajo, como mencioné en la introducción, analicé ciertos rasgos gramaticales del spanglish para poder cuestionar aquella tesis según la cual no se trataba de un lenguaje. En este mismo sentido, Ardila (2005) también estudia algunas construcciones en spanglish para plantear que existe un proceso de gramaticalización del spanglish según el cual éste podría ser catalogado como lengua, pensando nuevamente en que es necesario que una lengua cuente con gramática para que sea tomada como tal.

${ }^{17}$ Este tema será retomado en el apartado 2.2. Literaturas menores y lenguas madrastras.
} 
lingüísticas desde ese ámbito que luego se ancla en la política para generar gramáticas que estandarizan a las lenguas, que plantean a unas con cierto estatus mientras niegan a otras.

Aquí volvemos a Derrida (1997): la posibilidad de reapropiarse una lengua extranjera para poder hacerla propia es, al menos en algún sentido, un mecanismo de rebelión a la imposición de la lengua. Cuando una lengua es siempre ajena, cuando no es propia nunca, utilizarla es una manera de decir como Calibán en La Tempestad de Shakespeare: “me enseñaste a hablar, y mi provecho es que sé maldecir”. Utilizar la lengua impuesta es una forma de desterritorializarla, de reconocerse como extranjeros en la propia lengua y luego, utilizándola, reterritorializarse en esa lengua ${ }^{18}$. Pensando entonces que un lenguaje es una variedad de uso de una lengua y no el sistema de signos que la constituyen (Saussure 1945, 41), el spanglish se presenta como el uso de dos: del inglés y del español, y no como un dialecto de una lengua.

¿Qué es, entonces, una lengua? Hasta aquí hemos esbozado algunas de sus características: la planteamos como homogénea (en el sentido de la gramática), es oral (para ser objeto de estudio de la lingüística), puede tener escritura (como soporte), debe tener hablantes nativos, tiene literatura. Entonces, relacionamos estas características con lo político para decir que el concepto de 'lengua' (y las clasificaciones lingüísticas) se encuentra ligado a factores externos al sistema de las constantes gramaticales propias de la lengua. A partir de esto podemos decir, en el sentido en el que G. Agamben retoma a M. Foucault, que la lengua es un dispositivo, es decir, una red que se teje entre relaciones de poder, un conjunto heterogéneo "que incluye virtualmente cada cosa, sea discursiva o no (...). El dispositivo siempre tiene una función estratégica concreta, que siempre está inscrita en una relación de poder" $(2011,2)$. Este dispositivo de poder dicta qué estructuras producidas son gramaticales y cuáles no, dicta qué enunciados pueden formar parte de una lengua y cuáles, aun siendo producidos, serían agramaticales.

\footnotetext{
${ }^{18}$ No encontramos mejor manera de definir desterritorialización y reterritorialización, que retomando el ejemplo con el que Deleuze y Guattari ilustran estos dos procesos en Kafka por una literatura menor (1990): la boca se compone por dientes, lengua, paladar, músculos y tejidos dispuestos para morder, masticar y tragar. Sin embargo, utilizamos todo cuanto está en la boca para hablar: movemos la lengua hacia los dientes, hacia el paladar, expulsamos aire, producimos sonido; tomamos cuanto está en la boca para darle otro uso, distinto al de comer. Así, desterritorializamos la boca y la reterritorializamos, ahora usándola para el habla.
} 
Decimos, entonces, que para ser objeto de estudio de la lingüística, la lengua debe instituirse a partir de la oralidad, y que la escritura de una lengua sería solamente el soporte gráfico de ésta. Sin embargo, existen estructuras gramaticales que varían dependiendo de si aparecen en la escritura o en la oralidad, por lo que un acercamiento a la escritura desde la lingüística interna se vuelve necesario (como se verá en el siguiente apartado). Por otro lado, si bien el sistema linguiístico puede también presentar diferencias según las estructuras sociales a las que aparezca ligado (como lo plantea la sociolingüística), el hecho de que una lengua se tome como tal dependerá de otros factores, también políticos, que determinarán los límites de esta clasificación. Aquí el spanglish, entonces, aparece no como un dialecto, sino como un lenguaje que resulta de ese proceso político de la no-pertenencia a una lengua nacional. Finalmente, decimos que la escritura de una lengua es una forma de fijarla, y que la literatura es una herramienta para darle estatus. Por tanto, nos gustaría pensar sobre aquellas maneras en que las lenguas orales llegan a la escritura, a ese sistema que le da la posibilidad de estandarización mediante la ortografía y mediante la representación de los sonidos de la lengua. Este será el tema del siguiente apartado.

\subsection{Tecnologizar la palabra: de la oralidad a la escritura}

Como mencionábamos, la lingüística no se ha ocupado de estudiar la escritura en sí, como objeto de estudio, aunque sí se ha acercado a los distintos sistemas de escritura para analizar las lenguas. En este sentido, la escritura será un registro material de las lenguas, un "sistema secundario de modelado, que depende de un sistema primario anterior: la lengua hablada" (Ong 1987, 18) ${ }^{19}$, lo que nos permite acercarnos a su evolución. Es importante decir, también, que es a partir de la escritura que pueden presentarse los análisis gramaticales: la lingüística, pues, no estudia a la escritura pero la tiene presente siempre en su trabajo (Cfr. Culler 1989, 181).

\footnotetext{
${ }^{19}$ Es recurrente encontrar "lengua hablada" para hacer referencia a la lengua oral o de señas, es decir, a cualquier lengua no-escrita.
} 
La escritura, como la forma visual de las palabras, ha jugado un papel fundamental para la conservación de la memoria y, desde su relación con el lenguaje, ha permitido documentar y conocer la evolución de las lenguas e incluso ha permitido el estudio de lenguas muertas. Los documentos escritos, de la misma manera, han permitido un acercamiento antropológico y sociológico al funcionamiento de los grupos humanos. En este sentido, G. Cardona escribe, en Antropología de la escritura (1991), sobre la manera en que la lingüística se ha acercado a la escritura, distinguiendo dos maneras de lograr este acercamiento: primero, tomándola como registro material de las lenguas, para estudiar su evolución, y luego, tomando a la escritura como transcripción de la lengua oral, viendo a la oralidad y a la escritura como sistemas separados, en el que la segunda sería secundaria a la primera.

Para el mismo autor, la escritura se reparte en la sociedad de manera heterogénea, a diferencia de la lengua oral, cuya repartición tiende a ser homogénea (en el sentido en que todos los miembros de la sociedad tienen acceso a su adquisición). Esta repartición de la escritura dentro de la sociedad va ligada al funcionamiento de ésta, pues no todos los miembros de un grupo social tendrán el mismo acceso a la lengua escrita, literaria o no, lo que dependerá de factores como el acceso a la educación (un acceso que también se verá ligado a la cultura en el sentido en que ciertas escrituras serán producidas sólo por ciertos grupos). Como ejemplo de lo anterior, el autor habla de cómo escribir ciertas recetas medicinales o tatuajes era una tarea de las mujeres en ciertas sociedades, mientras que otras tareas, como la transcripción de libros, eran masculinas.

En un primer sentido, entonces, los sistemas de escritura de las lenguas se piensan como una forma de materializar los sonidos del lenguaje en la gráfica, es decir, como una forma de hacer a las palabras semejantes a las cosas (Ong 1987, 20). De aquí podríamos preguntarnos si la escritura es sólo una forma de representación de la lengua oral, o en qué sentido podría serlo, pues aunque la escritura surgió mucho tiempo después del origen del lenguaje y aunque retoma la oralidad para existir (Cardona 1991, 61), pueden notarse ciertas diferencias entre ambos sistemas, de manera que es imposible decir que son paralelos. La escritura, por ejemplo, permite mantener el lenguaje a través del tiempo, cancelando así la evanescencia de la oralidad, y puede participar también de soportes varios. De esta manera, 
es posible encontrar escritura en la arena, en hojas, rocas o telas, es decir, en materiales distintos al papel, con propiedades que tolerarán el paso del tiempo de maneras diferentes.

En este mismo sentido, P. Achard, en ¿La especificidad de lo escrito es de orden lingüístico o discursivo? (1991), trata de esbozar algunas diferencias entre la lengua escrita y la lengua oral, partiendo de elementos como el uso de ciertos tiempos en francés y ciertas características morfosintácticas que aparecen en la escritura pero no en la lengua oral pues, como dice, las estructuras de la lengua escrita suelen ser más prolijas que las de la lengua oral. Esta idea rompe con la concepción saussureana de la lengua escrita como transcripción de la lengua oral, pues se le reconoce como un uso distinto con ciertas particularidades. Otra de las características de la lengua escrita, que menciona Achard (1991), es la estructuración de los enunciados y las cadenas significantes, organización que generalmente no aparece en la lengua oral de la misma manera que en la lengua escrita, y que en la lengua escrita sólo se suspenderá cuando aparezca la escritura oralizada. De ahí que para Walter J. Ong (1987), una de las consecuencias de la escritura sea la posibilidad de estructurar el pensamiento (lo que para hablantes de lenguas con sistemas de escritura se verá reflejado luego en la oralidad, permitiendo así literaturas orales con estructuras heredadas de la escritura).

Como mencionábamos, la escritura permite un acercamiento al cambio lingüístico, por lo que a partir de ella es posible conocer la manera en que las lenguas se encuentran entre sí (por ejemplo, en el bilingüismo). A este respecto, Bloomfield, en Lenguaje (1964), menciona que los testimonios escritos y el estudio de éstos son una forma de acercarse al cambio lingüístico, partiendo de la escritura. En un apartado de este libro, Los testimonios escritos, el autor habla de los testimonios como materiales útiles para analizar la evolución de las lenguas, reflejada en la manera en que ciertas grafías van alternándose con otras para representar el cambio de ciertos sonidos. En este sentido, también la lengua escrita cambia conforme se da el cambio de la lengua oral. Aunque el análisis del cambio lingüístico a partir de la escritura presenta ciertas complicaciones, sobre todo si la lengua que se estudia no es conocida, permite ver el contacto entre las lenguas escritas a partir de los sistemas de escritura que un hablante puede hacer. Como ejemplo de lo anterior, puede verse cómo un hablante bilingüe, con desconocimiento del sistema de escritura de una de las lenguas que habla, puede tomar el sistema de escritura de la otra lengua para escribir ambas. Es importante señalar que 
el cambio del sistema lingüístico en su dimensión oral no siempre se ve reflejado en el cambio de la escritura, pues no necesariamente evolucionan de manera simultánea. Como ejemplo de esto podemos ver el caso de la escritura del francés, cuyos cambios han sido más conservadores en la escritura con relación a la oralidad, donde ciertos sonidos se han perdido aunque permanecen en la ortografía de la lengua.

También es necesario hacer la distinción entre la presencia de un autor en cada uno de los casos: mientras que en la oralidad el discurso siempre se encuentra ligado al autor, en la escritura siempre se encuentra separado: esto permite que las interacciones de la lengua oral sean directas, a diferencia de las interacciones con el autor virtual de una obra escrita (Ong 1987, 81). La oralidad, pues, vive en un lugar y momentos determinados que la escritura puede transgredir.

Al inicio de este apartado hablábamos de la escritura como una forma de tecnología, ¿en qué sentidos? Quizá aquí valdrá la pena hacer una distinción entre el sistema lingüístico de la escritura (que, como decíamos, permite un uso del lenguaje distinto de aquél que aparece en la oralidad) y su forma visual (gráfica, impresa o dibujada). En ambos casos, la escritura funciona como una tecnología, como una serie de herramientas primero arquitectónicas, para el pensamiento, y luego como una tecnología que utiliza prótesis (a las manos, dedos y brazos) como herramientas para generar esa escritura. En palabras de J. Ong, "las tecnologías no son sólo recursos externos, sino también transformaciones interiores de la conciencia, y mucho más cuando afectan a la palabra" $(1987,85)$.

La relación entre la lengua hablada y la lengua escrita, entonces, se ha trazado de manera que la escritura se ha tomado como una forma de tener acceso a la lengua y a los cambios de ésta, como una forma de representación de la lengua oral que, como decíamos, no funciona solamente así, pues la lengua escrita genera también sus propias reglas. Sin embargo, la lingüística se ha acercado al estudio de la escritura en tanto manifestación del lenguaje, no sólo a partir de su materialidad, sino por las posibilidades de creación lingüística que abre. Como mencionábamos en el apartado anterior, la escritura no ha sido tema de la lingüística pero la lingüística no puede trabajar si no es a partir de la escritura de las lenguas. Por tanto, el tema del siguiente punto surge a partir de este cuestionamiento sobre las maneras 
en que la lingüística, que ha estudiado a las lenguas primero en su dimensión sonora, puede trazar un posible acercamiento hacia la escritura de los sistemas lingüísticos.

\subsection{Lingüística de la escritura}

Como mencionamos en el apartado anterior, la lingüística se ha acercado a la escritura en tanto que ésta representa una materialidad distinta a la del lenguaje oral. En este sentido, algunas de las diferencias que presenta con el lenguaje oral serán la permanencia en el tiempo y la posibilidad de llevar el lenguaje a puntos espaciales distintos a aquellos en lo que se produjo (Bloomfield 1964, 347). Sin embargo, partiendo de la idea de que la escritura presenta ciertas estrategias y características lingüísticas particulares, algunos autores como J. Culler, han propuesto un acercamiento meramente lingüístico a la escritura.

En Hacia una lingüística de la escritura (1989), Culler habla sobre cómo la lingüística, pese a su dependencia de la escritura, ha dejado de lado el estudio de los valores asociados a la lengua escrita, lo que constituiría concretamente la tarea de la lingüística de la escritura. En este sentido, el autor concibe a la escritura de una lengua como su forma de creación lingüística y como una manifestación material del lenguaje. Esta materialidad resulta significativa en distintos niveles, pues implica usos del lenguaje y de los mecanismos de éste que evocan afectaciones (al lector) no necesariamente codificadas en los signos escritos. Es decir, en la escritura literaria, por ejemplo, podemos encontrar ciertos elementos, mensajes o sensaciones evocados por la escritura misma y que exceden a la lengua escrita como transcripción de la lengua oral. La escritura, por tanto, no puede resumirse en una cadena de signos gráficos correspondientes a una cadena de signos sonoros, pues el uso del lenguaje escrito conlleva otros aspectos. La poesía puede servir de ejemplo para ilustrar lo anterior, no sólo por la sonoridad que implica su escritura, sino también por la manera en que, como ejercicio gráfico, es un uso del lenguaje en el que los signos se disponen de 
maneras particulares, espacialmente, por un lado, pero también en la misma elección que se hace en la escritura para representar cierta palabra de una manera particular y no de otra ${ }^{20}$.

Según lo expuesto en el apartado anterior, la escritura en tanto uso del lenguaje, permite también trazar ciertas relaciones con la cultura, la historia y, en este sentido, con lo político, relaciones que se pueden ver en la escritura literaria, como hemos venido mencionando. En este sentido, N. Fabb y A. Durant, en Nuevas tendencias de la lingüística de la escritura (1989), mencionan que dichas relaciones pueden desentrañarse entre los textos y los aspectos de la realidad social porque las obras literarias reflejan ciertos aspectos sobre la sociedad codificados en el uso mismo del lenguaje y no sólo en la conformación de las obras. En este sentido, el lenguaje en la escritura literaria participa de ciertas características que permiten ligarla a aspectos culturales, como la identificación de un grupo a partir de ciertos usos del lenguaje, plasmados en la literatura, lo que es posible tomando en cuenta el contexto de producción de cada obra en particular.

De tal manera, el lenguaje en la escritura literaria excede a la obra, pues conlleva una serie de implicaciones que no siempre se ven reflejadas en la cadena de signos lingüísticos en sí. Así, analizar lo dicho en las escrituras en spanglish, por ejemplo, lleva a pensar el contexto de estas escrituras en relación con la historia de la comunidad que las escribe, pensando que los autores de tales obras participan de contextos específicos desde los cuales escriben. Aunque este aspecto será expuesto más tarde, es importante mencionar que la razón de estudiar la literatura desde la lingüística consiste, entonces, en ver cómo se trazan esas relaciones entre el lenguaje plasmado en la obra, aquello que se dice, las evocaciones que generan las palabras escritas, y sus implicaciones en el ámbito social.

Así, la literatura chicana, siendo una literatura generalmente de denuncia, tiene repercusiones en la comunidad que lee, pero participa a su vez de un contexto político, social y cultural que las hace nacer, y que repercute en el uso del lenguaje que hacen los autores al escribirla. Lo anterior permite trazar también una relación entre el lenguaje y la literatura en

\footnotetext{
${ }^{20}$ Respecto a esto último, podemos hablar de la literatura en spanglish, particularmente de la literatura poética, como de un uso del lenguaje en el que la escritura misma de las palabras, fuera de las convenciones ortográficas, evoca ciertos sonidos e incluso ciertos mensajes particulares que se notarán en la interpretación, aunque esto será retomado más adelante.
} 
varios sentidos, que serán el tema del siguiente apartado, pensando a las escrituras literarias como usos del lenguaje, pero sin perder de vista las implicaciones que conlleva escribir en una lengua en una situación histórica y política específica.

\section{II. ¿Qué es la literatura?}

Cuando pensamos en la escritura de una lengua decimos que hablamos de una forma gráfica del lenguaje. Pero cuando hablamos de literatura, aunque hablamos también de un uso del lenguaje, hablamos de creación lingüística, tendemos a trazar una línea que nos lleva a pensar en lo estético de estas formas del lenguaje escritas. La literatura, sin embargo, es anterior a la escritura, en sus formas más antiguas, aunque la ha tomado como soporte material y como forma de estructuración, constituyéndose actualmente como una variante de la escritura. La literatura, pues, ha evolucionado: donde antes encontrábamos que era únicamente oral, luego pasó a ser escrita y ahora podemos encontrarla en ambos soportes, sonoro y visual, con las particularidades de cada uno, con sus semejanzas y diferencias.

Hemos dicho, hasta ahora, cómo se ha tomado la escritura desde la lingüística, y esto nos permite ahora plantearnos la pregunta sobre cómo puede lograrse un acercamiento lingüístico a la literatura, para verla como un uso del lenguaje. Así, en los siguientes apartados trataremos esta cuestión en dos sentidos: primero, con base en lo que plantea Foucault, para luego hablar sobre las relaciones entre el aspecto político del uso de la lengua a partir de la literatura, partiendo de aquellos aspectos mencionados anteriormente sobre las implicaciones de escribir en una lengua impuesta. 


\subsection{La literatura como uso del lenguaje}

En este punto, según La gran extranjera: para pensar la literatura de M. Foucault (2015), veremos cómo la literatura se relaciona con la lengua, en tanto que es un acto de ésta cuyo nacimiento está ligado por un lado al uso del lenguaje y, por otro, al nacimiento de la obra en el acto mismo de la escritura. Para Foucault, la literatura pasa por el vértice de la obra para conectarse con el lenguaje, y en tanto que necesita de éste para existir, participa de la semiótica cultural que se codifica en las palabras y de la gramática de la lengua para darse a entender, en un sentido más cercano a la comunicación que a la expresión. La literatura juega con la evanescencia del lenguaje al posibilitar que se mantenga a través del tiempo en la obra, juega con la repetición del lenguaje al crear espacios en los que una misma frase, escrita por autores diferentes, adquiere significados distintos (al ser parte de nuevos discursos), y permite también jugar con las formas de la gramática, en el límite en el que lenguaje y locura se juntan: el uso del lenguaje en la literatura permite la creación de un nuevo lenguaje literario que no se separa por completo de la gramática, pues sería un lenguaje de locos, no comprensible para el resto de los hablantes de una lengua, pero sí irrumpe con aquello ya dicho, permitiendo la búsqueda de la libertad a partir de las palabras.

En este sentido, Foucault (2015) habla de cuatro niveles en los que es posible conectar a la literatura con el lenguaje: en el nivel de los signos culturales (literatura como combinación de signos verbales, que participan de una semiótica cultural para su construcción), en el nivel del uso del lenguaje (las elecciones que se hacen sobre un uso u otro), en el nivel de la escritura (signos que la literatura usa para significarse a sí misma) y en el nivel de las implicaciones (signos con los que una obra se representa a sí misma, en su relato). Lo anterior permite explicar a la literatura en la medida en que se conforma por enunciados, como también dice Foucault, y que en este sentido es lenguaje, tomándolo como sistema de la lengua, pero también como conformación histórica en donde resuenan otras palabras. Así, un uso del lenguaje implica una irrupción con aquello que se ha dicho antes, pero no se deslinda por completo de ello; hace uso de nuevas estructuras y dota a las palabras y frases con nuevos sentidos, pero sin perder de vista aquello que han implicado, sin salirse de la gramática pero llevándola a nuevos sitios. Es a partir de estos nuevos sitios que se conforma la obra literaria, pues si bien sigue apareciendo el lenguaje como sistema, se 
suspende a la gramática en el tiempo y en el espacio, haciendo que el lenguaje literario se conforme a sí mismo a partir de la literatura.

A partir de lo anterior, el lenguaje en la literatura dice mucho más de lo que se plasma en la obra en sí. Plantea, como decíamos anteriormente, relaciones con aquello que excede a la obra, conformando enunciados: un enunciado, para Foucault, excede a las palabras, las frases, las proposiciones y los actos de habla, por lo que para acceder a ellos es necesario conformar un corpus que retome las formaciones históricas de las que son parte, que los conforman.

A este respecto, Deleuze (2013) propone una metodología para extraer enunciados de estos usos lingüísticos, literarios o no, partiendo de Foucault. En primer lugar, propone la conformación de un corpus histórico del cual se tomarán los enunciados, y desde el cual pueden trazarse singularidades. Los enunciados participan del sistema de la lengua pero en el uso de ésta, lo que lleva a pensar la heterogeneidad de la lengua en tanto que cada uso es una irrupción, es distinto a los otros usos ya hechos (en el sentido mismo con el que se cargan, pues aún si una estructura se repite, se cargará de nuevos significados en la obra en la que aparece). Esto último será el segundo paso para extraer enunciados: ver en qué sentido esos usos del lenguaje son significativos, de qué manera implican irrupciones y respecto a qué. Esto, para Foucault, es ser lenguaje: éste se conforma por signos, pero no limita a ellos, sino que las cadenas de signos en el uso del lenguaje, se dispersan en múltiples direcciones, siempre guiadas por la lengua misma. Es decir: el lenguaje no excede a la gramática, pero en el uso la lleva a su límite. Para Foucault, es en la literatura donde esto se ve claramente, pues en su disposición espacial juega con los usos del lenguaje explotando sus características, y al mismo tiempo permite la agrupación del lenguaje más allá de la representación en sí: conformada por enunciados, la literatura traza relaciones con lo ya dicho, irrumpe con ello, crea nuevos sentidos, plantea nuevas posibilidades de uso del lenguaje.

De tal manera, el uso del lenguaje que aparece en la literatura se cargará de ciertas particularidades, que aparecen también en la elección misma de la lengua que toma quien escribe. Esa elección será política, no sólo implicará una irrupción con lo ya dicho dentro de la obra, sino también fuera de ella. En este sentido, en el siguiente apartado hablaremos de 
cómo la elección de la lengua para la creación literaria traza relaciones con lo político, fuera de la obra, pero sí partiendo de ella.

Es importante decir que, partiendo de lo expuesto anteriormente, para Foucault un enunciado no ocurre aislado de lo que se ha dicho antes, por lo que es necesaria la conformación de dos herramientas de trabajo para en análisis de los discursos: un corpus histórico y un archivo. Retomando al autor, un corpus de enunciados tendrá que ser un corpus histórico, construido con enunciados (sean palabras, frases, proposiciones o textos completos) a partir de los cuales, en conjunto, podrá verse aquello dicho. En este sentido, propone el concepto de archivo, compuesto por todos los sistemas de enunciados:

Entre la lengua que define el sistema de construcción de las frases posibles, y el corpus que recoge pasivamente las palabras pronunciadas, el archivo define un nivel particular: el de una práctica que hace surgir una multiplicidad de enunciados como otros acontecimientos regulares (...). Es el sistema general de la formación y la transformación de los enunciados

(Foucault 2017, 171)

Deleuze (2013) recupera la noción anterior de Foucault para explicar esa multiplicidad de enunciados, dada por la heterogeneidad de la existencia de éstos y por sus reglas de dispersión, es decir, por aquellas reglas que les permiten variar. Este sistema que forma a los enunciados y que les permite transformarse es, entonces, el archivo. El corpus, por otro lado, sí es un conjunto de enunciados, es decir, de actuaciones, a partir del cual es posible extraer singularidades: aunque los enunciados que conformen al corpus no sean heterogéneos, es posible ver la conformación de cierto discurso en esa familia (no homogénea) de enunciados. Es importante decir, también, que el corpus histórico que propone Foucault se distingue del corpus de la linguiística en, al menos, dos sentidos: el corpus histórico no es sincrónico, sino que al conformarse por enunciados retoma la potencia del discurso para irrumpir con lo dicho anteriormente, es decir, se relaciona con lo que ha sido dicho; también, este corpus foucaultiano se compone de enunciados, es decir, de unidades reales del discurso, no de oraciones ni de estructuras posibles. En este sentido, el archivo será el conjunto de discursos que han sido dichos a partir de los cuales se determinan 
los límites de los enunciados posibles, cuáles pueden decirse, cuáles pasarán a la memoria, y que se desenmaraña a partir de la arqueología.

De tal manera, un corpus de la literatura latina en spanglish tendría que componerse por enunciados de distintas literaturas que retoman ambas lenguas: la literatura chicana, pero también la literatura puertorriqueña, dominicana, salvadoreña, cubana y de otras comunidades. Este tema será recuperado en el tercer apartado, donde expondremos cómo puede conformarse un archivo de la literatura en spanglish, partiendo de las nociones anteriores para el análisis.

\subsection{Literaturas menores y lenguas madrastras}

La literatura, como dijimos, es un uso del lenguaje. En este uso del lenguaje, aparecen varios aspectos sobre la posición de la lengua en la literatura, pues escribir puede ser un acto político en ciertos sentidos. Así, la literatura en spanglish en Estados Unidos implica un uso del inglés y del español en una obra determinada, pero también en un contexto específico: aquel en el que el inglés es una lengua reconocida. En este sentido, el inglés es una lengua mayor, retomada para la escritura por escritores latinos cuyo uso del inglés es reconocido como ilegítimo. De la misma manera, las escrituras literarias de ciertos escritores latinos, aun cuando se crean en una sola lengua, implican la reapropiación de esa lengua por parte de quien hace uso de ella para construir sus narrativas. Cuando un escritor toma una lengua distinta de su lengua materna para la escritura, traza ciertas relaciones, políticas y culturales, con ella.

Deleuze y Guattari (1990) hablan de las literaturas menores como aquellas literaturas que, aun siendo expresadas en lenguas de reconocimiento mayor, son escritas por una minoría (una minoría no numérica sino en el sentido de su reconocimiento). Las literaturas menores tienen tres características: desterritorializan a la lengua (creadas en una lengua mayor por un grupo de habla minorizado, retoman esa lengua mayor para cargarla de nuevos sentidos), son políticas (al no ser reconocidas, se conectan con la política), y son colectivas (aun cuando 
son creadas individualmente, son manifestaciones colectivas, pues pertenecen a un grupo). Estas literaturas se niegan a pertenecer a la literatura mayor, y esto se ve plasmado en el uso mismo del lenguaje, desde sus estructuras gramaticales: escribir literatura menor, en una lengua mayor, puede implicar no hacer un uso correcto de esa lengua, llevando su gramática al límite. En este sentido, Deleuze y Guattari dicen:

¿Cuántos viven hoy en una lengua que no es la suya? ¿Cuánta gente ya no sabe ni siquiera su lengua o no la conoce todavía y conoce mal la lengua mayor que está obligada a usar? Problema de los inmigrantes y sobre todo de sus hijos. Problema de las minorías. Problema de una literatura menor.

$(1990,33)$

Partiendo de esto, decimos que la literatura en spanglish es una literatura menor: se conforma de dos lenguas mayoritarias, ambas con miles de hablantes, pero aparece en un lenguaje de las minorías, de aquellas que pese a ser bastante numerosas no pueden lograr un reconocimiento por parte de los que hablan lenguas estándar, lenguas reconocidas. Aún en los casos en los que dichas literaturas en spanglish aparecen sólo en una de las dos lenguas, casos que serán expuestos más tarde, esos usos de la lengua serán usos menores, implicarán un devenir-menor de la lengua-mayor, conformarán un espacio en el que los escritores en spanglish devienen extranjeros en la propia lengua.

De tal manera, escribir literatura menor implica tomar una lengua que ha sido impuesta a un grupo para la creación linguiística a partir de ella. En este sentido, el problema de las literaturas menores está ligado al problema de escribir en una lengua madrastra, concepto propuesto por G. Borioli (2013) para explicar esa situación consistente en una lengua ajena que un autor adopta para la escritura. Esto conlleva un sentido político: implica un posicionamiento de quien escribe respecto a su lengua materna, que no retomará para la escritura, pero también respecto a la lengua en la que escribe, es decir, a la lengua madrastra. Dichas lenguas implican que un sujeto deje su lengua materna para escribir en otra, con la que no se identifica, pero que retoma para la creación lingüística, creando así un territorio migrante en la lengua, siendo extranjero en ella. Quizá este concepto puede resultar análogo 
a lo expuesto por J. Derrida en El monolingüismo del otro $^{21}$ : la lengua impuesta es siempre ajena, pero aun cuando esa lengua impuesta se hable como lengua materna, resonarán en ella los ecos de esa otra lengua arrebatada: "no tengo más que una lengua y no es la mía, mi lengua "propia" es una lengua inadmisible para mí. Mi lengua, la única que me escucho hablar, es lengua del otro" $(1997,16)$.

Como decíamos, una de las características de las literaturas menores será el fuerte coeficiente de desterritorialización (Deleuze y Guattari 1990) que afecta al lenguaje. En el caso del spanglish, esta desterritorialización no se da en un sólo sentido, no es únicamente la falta de un territorio geográfico delimitado, sino que también se muestra a partir de las palabras que lo conforman, palabras de culturas e identidades híbridas, que no son ya ni mexicanas (o latinoamericanas) ni estadounidenses, sino que son chicanas, pochas, cholas, chúntaras, latinas. Las literaturas en spanglish han aceptado una marginalidad creada a partir de dos lenguas mayores y de dos culturas que han confluido no sólo territorialmente sino también históricamente (Cfr. Arteaga 1994).

En el mismo sentido, Derrida (1997) habla de la metrópoli como aquel territorio al que pertenece la lengua materna, esa lengua que puede ser apropiada por aquellos hablantes a quienes, sin embargo, se les ha asignado como lengua materna. En el caso del spanglish, esta metrópoli se presenta difusa. Cuando Derrida plantea esta idea, lo hace pensando en el caso particular del francés impuesto en Argelia que, pese a esa distancia geográfica, sigue encontrando su territorio en Francia. Pero al hablar inglés en Estados Unidos, la comunidad latina está fuera de la lengua aunque se encuentre dentro del territorio de esa lengua; y cuando esa misma comunidad regresa a la tierra de la lengua mítica, a las naciones latinoamericanas, el uso del español siempre estará, también, fuera del uso estándar, siempre será un español extranjero. Estos dos usos de la lengua serán también reconocidos aquí como usos del spanglish, pues aunque retomen sólo la gramática de una de las dos lenguas, aparecerán en ellas las memorias de esa lengua cuya apropiación ha sido negada.

Los conceptos anteriores no son aplicables únicamente para las escrituras en spanglish, pues a lo largo de la historia de la literatura han sido varios los autores que han escrito en una lengua distinta a su lengua materna, o que lo han hecho en una lengua que se

${ }^{21}$ Retomado brevemente en el primer apartado del presente trabajo (1.1. ¿Qué es una lengua?) 
les ha impuesto como lengua mayor, pero en la que se presentan con un uso menor del lenguaje. Como ejemplo de esto podemos encontrar la literatura de F. Kafka, J. Joyce o S. Beckett: Kafka escribiendo en alemán, Joyce y Beckett escribiendo en inglés. Como mencionan Deleuze y Guattari $(1990,39)$, incluso el uso del francés que aparece en las películas de Godard o, más recientemente, en las novelas de Virgine Despentes, implica un uso menor de la lengua, pues se retoman frases del francés que están al margen de lo estándar, una situación que implica ser extranjero en la propia lengua: incluso cuando quien la utiliza ha adquirido la gramática de esa lengua como la de su lengua materna, escribir literatura menor en una lengua mayor es tomar una gramática identitariamente ajena, para hacer uso de ella.

Una lengua madrastra, en palabras de Gloria Borioli, "no se elige porque sí. En realidad, no se elige: viene sobredeterminada por el imperativo de ser aceptado en un universo más amplio que el de la socialización primaria, está dada por un orden comunitario en el cual la escucha tiene un precio, un aprendizaje, un código; porque para ser recibidos en ese colectivo extenso los sujetos deben adquirir unas habilidades comunicativas" (2013, 189). En este sentido, utilizar una lengua madrastra implica retomar un sistema de signos ajenos y hacerlos propios, aunque no se haya aprendido a vivir con ellos como en una lengua materna. Quizá partiendo de esto podríamos preguntar, ¿cuándo se impone una lengua? ¿Qué implica utilizar una lengua impuesta?

En este punto, vale la pena retomar dos casos para ilustrar los conceptos de literatura menor y lengua madrastra, pero también para mostrar que, como se decía, habitar una lengua madrastra no es algo que ocurra sólo para los escritores en spanglish. Los dos casos que se retomarán son, por un lado, la situación del dialecto argen-mex descrita por Pedro Sonderéguer (2015) y el uso del verlan en la literatura de Vrigine Despentes, por otro.

Pedro Sonderéguer describe al argen-mex como un dialecto hablado en la Ciudad de México por hijos de padres argentinos exiliados durante la última dictadura en Argentina (y que llegaron a México a partir de 1976). En palabras del autor, este dialecto y su nombre mismo se adoptan para ser utilizados como una forma de aceptar la nacionalidad mexicana 
sin negar la argentina ${ }^{22}$. El argen-mex nos permite pensar en los límites de una lengua madrastra: si bien podríamos pensar en las condiciones de esos migrantes argentinos y de sus hijos no son las mismas de aquellos que migran hacia Estados Unidos sin recibir asilo político legal, y que además migran hacia otra lengua con la que la suya no comparte reglas gramaticales, sí podemos decir que adaptarse a otro dialecto desde el propio implica utilizar una lengua en otros sentidos que son ajenos y que se imponen para lograr la comunicación.

Por otro lado, las tres características de las literaturas menores pueden verse ejemplificadas en algunas novelas de Virgine Despentes, como Vernon Subutex, pues como dice Thomas Muzart (2018), la literatura de esta autora francesa retoma el slang francés y el verlan (juego lingüístico en el que se altera el orden de las sílabas, sobre todo el palabras disilábicas ${ }^{23}$ ) para hablar de las experiencias de sus personajes, retomando esos usos del lenguaje como usos que conforman su identidad. En este sentido, la literatura de Despentes se plantea como una literatura menor en la que se desterritorializa la lengua, pues se retoma un uso menor, no reconocido del lenguaje; es también una literatura en la que todo es político pues incluso el uso del lenguaje (el slang y el verlan) aparece como parte de la identificación de un grupo; así mismo, en su literatura todo toma un sentido colectivo pues retoman un sentido de pertenencia a una comunidad, aunque se escriba desde la individualidad (Muzart 2018, 165). En este sentido, el autor dice que en la literatura de esta autora aparece una consciencia sobre el uso del lenguaje que permite plantear una crítica a un sistema que excluye, lingüísticamente, a quienes no hacen un uso del francés desde la gramática estándar y que, para el caso del slang franco-árabe, también forman parte de una comunidad de migrantes que ha retomado al francés como su lengua de trabajo.

Cristina Rivera (2018), por otro lado, retoma de Silvia Rivera Cusicanqui (historiadora y socióloga aymara, directora del Colectivo Ch'ixi) el concepto de

\footnotetext{
${ }^{22}$ Algunas características lingüísticas de este dialecto, descritas por el autor, son: /s/ aspirada en posición intervocálica o velarizada en fin de sílaba preconsonántica (aunque esto no ocurre en todos los casos); rehilamiento (o zeísmo) tomado del dialecto argentino ([ze.g'o] para "llegó") y yeísmo tomado del dialecto mexicano ([ya.ma] por "llama"); elisión de consonantes en final de palabra, tomado del dialecto mexicano ([kr'a] por "crack"); confusión de las formas "vos" y "tú"; tendencia a incorporar diminutivos, tomado del dialecto mexicano; uso frecuente de tiempos compuestos, tomados del dialecto mexicano; incorporación de algunos elementos léxicos como "gilada", "cacho", "berreta", chau", "sorete", al dialecto mexicano.

${ }^{23}$ Como ejemplos del verlan, el autor retoma "meuf" por "femme" ('mujer'); "keuf” por "flic" ('policía'); "feuj” por "juif" ("judío'). Todos son ejemplos tomados de las novelas de Despentes.
} 
epistemología ch 'ixi para hablar de lenguas ch'ixi, lenguas que participan del mismo sistema al que buscan demoler ${ }^{24}$. Para Rivera Garza, cuando un autor migrante latinoamericano retoma el inglés o el español para escribir en Estados Unidos, está tomando una lengua como lengua ch'ixi, o como lengua madrastra, utilizando su sistema para decir aquello que de otra forma no podría expresar, en una lengua que aunque le ha sido impuesta no ha logrado callarle. Escribir en estos sentidos, dice Rivera Cusicanqui, implica "utilizar y al mismo tiempo demoler la razón instrumental y sus múltiples lenguajes” (cit. por Rivera 2018).

Desde el caso del argen-mex y del verlan, podríamos decir que si bien una lengua madrastra se impone (como una lengua colonial) desde una posición de poder mayor hacia hablantes de una lengua menor, esto no es absoluto, pues como dice Cristina Rivera Garza:

El español, impuesto por la conquista y una experiencia colonizadora de al menos 300 años, es sin duda una lengua con Estado y ejército dentro de los territorios que conocemos como Latinoamérica (con la evidente excepción de Brasil y algunos otros países). Sin embargo, una vez que el español cruza una de las fronteras más dramáticas y poderosas de nuestro mundo globalizado sobre los hombros y en las bocas de los migrantes indocumentados (y no), se convierte también en una lengua sin Estado y sin ejército.

El inglés se convierte en una lengua madrastra utilizada por esos migrantes latinoamericanos para la creación de literaturas menores.

Podríamos decir, entonces, que las lenguas madrastras y las lenguas ch'ixi son similares: estas lenguas son desterritorializadas y reterritorializantes, son lenguas no reconocidas, ilegítimas, lenguas sin estado, sin metrópoli, son usos menores de sistemas lingüísticos mayores, usos manchados por la colonización, por el despojo (de cultura, de tierra, de lengua), por la implantación de la lengua, son lenguas con memoria nunca escrita en ellas. La creación de una literatura menor, como lo planteaban Deleuze y Guattari, será entonces una literatura escrita en una lengua que deviene menor, en una lengua ch'ixi, en una

\footnotetext{
24 "Ch'ixi”, en aymara, es una palabra que refiere a una mezcla pero que, para Rivera Cusicanqui, se diferencia de lo híbrido en tanto que esto último resulta en algo infértil (al respecto ejemplifica con el caso de las mulas, que son híbridas e incapaces de reproducirse). No así lo ch'ixi, que siempre resulta en algo nuevo, a partir de un proceso dialéctico que no niega aquello otro que lo conforma, sino que lo retoma. Al respecto se puede consultar su ensayo La universalidad de lo ch'ixi: miradas de Waman Puma (2009).
} 
lengua madrastra; puede plantearse como literatura monolingüe, pero en ese monolingüismo que es ajeno en tanto que quien lo usa se encuentra siempre como extranjero en él.

\subsection{Hacia un análisis discursivo de la literatura en spanglish}

Como hemos venido mencionando, es posible trazar ciertas conexiones entre la cultura y la lengua, en el caso específico de la literatura en spanglish, pensándolo desde el contexto específico de aquellos autores que lo utilizan para su escritura o que lo retoman como tema de ésta. De tal manera, en el presente apartado hablaremos brevemente sobre las distintas formas en que el spanglish ha aparecido en la literatura, desde el movimiento chicano, prestando atención también a las escrituras del presente siglo, para establecer sus diferencias en el uso del lenguaje, en sus intenciones y en su relación con la posición política de las comunidades latinas.

Partiremos de un análisis discursivo de escrituras poéticas, literarias, escritas en espanglish y en spanglish, en el sentido en que consideramos que es a partir del discurso que pueden verse aquellas relaciones entre la lengua y la literatura como uso del lenguaje con los aspectos políticos entramados entre ambos conceptos. El análisis del discurso, a diferencia de otras disciplinas de la lingüística, permite ahondar en aquello que ha sido dicho tomando en cuenta la historia de las comunidades que utilizan al spanglish y el contexto político en el que surge cada enunciado para decir lo que dice, pues es a partir de un método complejo que puede leerse un problema complejo como el del uso del lenguaje (spanglish) en la literatura. De tal forma, no veremos las variaciones dentro del sistema lingüístico a partir de las estructuras sociales, no partiremos a ver si ciertas estructuras producidas son o no gramaticales, no consideraremos su posibilidad como estructuras potenciales de una lengua, sino que abordaremos aquello que ha sido en realidad dicho para tratar de conocer lo que dicen; cómo y cuándo han sido producidos esos enunciados será, aquí, el asunto sobre el que escribiremos en los siguientes apartados. 
Para lo anterior, se expondrán algunos conceptos de Bajtín, Bourdieu, Foucault y Benveniste, en tanto resultan operativos para analizar las producciones escritas en spanglish como producciones discursivas. En este sentido, las presentes nociones serán utilizadas en el análisis que se presenta en el siguiente apartado, partiendo de la pretensión de analizar las escrituras poéticas en spanglish como usos concretos del lenguaje que trazan relaciones con la cultura y con las situaciones específicas de los escritores, por lo que las consideramos como escrituras políticas, una condición que se apreciará como un murmullo que resuena en dichas escrituras, y que los autores propuestos recuperan del discurso.

Así pues, para Bajtín, el enunciado se define como la unidad real de la comunicación discursiva, entendiendo como discurso un proceso de habla conformado por una serie de enunciados. Para el autor, una palabra existe primero como palabra neutra, en tanto que no pertenece a nadie, luego existe como palabra ajena, en tanto que se conforma de otros discursos y enunciados y, finalmente, existe como palabra propia cuando se actualiza en una situación discursiva específica (Bajtín 1989, 278). Es decir, una palabra existe como palabra de la lengua, pero, al enunciarse, se conforma por otros discursos que resuenan en ella; no es una palabra vacía, sino que al ser enunciada forma parte de una cadena, se encuentra en un momento específico pero no deja de participar de otros. Sin embargo, al ser utilizada por un hablante concreto en una situación determinada, adquiere un nuevo sentido, y es este nuevo sentido, esta nueva carga, la que hace que una palabra sea propia.

Para ver las relaciones entre la escritura y el reconocimiento de la lengua, volveré al trabajo de J. Culler (1989), porque toma a la lengua escrita como una forma de creación lingüística en su relación material con el lenguaje y con la palabra hablada. Se recurrirá también la sociología de la escritura, de Giorgio R. Cardona (1991) para plantear que las escrituras en spanglish implican distintas relaciones entre los escritores, los lectores y las editoriales. Al ser la escritura una de las formas menos uniformemente 'repartidas' en la sociedad (pues no todos los miembros de una sociedad tienen acceso a ella), su conocimiento y uso implican un anclaje en la sociedad y en el funcionamiento de ésta.

Como se mencionó, se trabajará a partir del análisis del discurso que, para Bajtín, se construye en la enunciación y, en este sentido, sólo existe en la forma de enunciados concretos, nunca aislados, siempre relacionados con enunciados subsecuentes y precedentes. 
Bajtín propone hablar de géneros discursivos, que se generan en cada esfera de uso lingüístico como "tipos relativamente estables de enunciados” (Bajtín 1989, 248), es decir, como grupos de enunciados con características comunes y que pueden dividirse en géneros discursivos primarios (principalmente géneros orales, pues se forman en la comunicación inmediata, en tiempo real) y géneros discursivos secundarios o complejos (que son una representación de los simples, generalmente en la escritura aunque no siempre). Bajtín ve al enunciado como una unidad individual, lo que se relaciona con la idea de lengua nacional en tanto que ese enunciado, al ser individual, es una forma de la lengua nacional.

Para Benveniste, por otro lado, el discurso existe como práctica enunciativa que se sitúa en un lugar y momento específicos (el cronotopo de Bajtín). Para él, la lengua no existe sino como mera posibilidad hasta el momento en que es usada por un acto individual de enunciación, lo que constituye al enunciado. En esa enunciación se produce una relación yotú-él que, en la situación espacio-temporal de la escena enunciativa, planteará las coordenadas para que se posicione un ego que enuncie el discurso. En este sentido, Benveniste plantea que aquello que se enuncia forma parte de una cadena temporal en la que el discurso ya se ha dicho, no es, pues, la posibilidad de decir algo sino aquello que se dice, y que para el analista del discurso siempre queda en el pasado, lo que implica un presente discursivo que continuamente se va actualizando. De Benveniste se retomarán también los conceptos de locutor, colocutor y alocutario, en tanto que permiten trazar relaciones entre los participantes de una escena enunciativa concreta. Para Benveniste, locutor es el yo que se apropia la lengua en el discurso y que se dirige a un alocutario, quien será también colocutor en tanto que crea un consenso pragmático con el locutor a partir del cual es posible la comunicación.

En el sentido en que para Benveniste un enunciado ocurre en un espacio y tiempo, para Foucault, por otro lado, ocurre en una posición histórica, lo que hace que se transforme en un acontecimiento histórico. Benveniste también habla de acontecimientos, pero no de la misma manera que Foucault, pues los toma como series de bloques que se disponen en el tiempo, como experiencias que se conectan en el tiempo crónico (el tiempo de nuestra visión del mundo) y que fluyen en el tiempo físico (el tiempo del mundo). Para Foucault, los enunciados son acontecimientos, que se actualizan con la palabra o con la escritura (donde 
permanecen), en tanto que aún su repetición implica la diferencia, pues la ocurrencia de cada uno es única en la historia, pero al igual que los enunciados para Bajtín, forman parte de una cadena con enunciados que les preceden y enunciados que les siguen. Foucault ve que en un conjunto de signos, la gramática puede reconocer una frase (y la lógica, una proposición), y en una de las formas de existencia de ese conjunto de signos es que se puede reconocer un enunciado.

Para Foucault, el discurso es un conjunto de actuaciones verbales (entre las que se sitúan los enunciados), precedido por otros discursos que ya han sido dichos, pero también por otros que no se han dicho. Los discursos, para Foucault, tienen reglas de dispersión, es decir, trazan relaciones, correlaciones, posiciones y funcionamientos que establecen sistemas de dispersión hacia otros discursos, y que constituyen una formación discursiva. Esta formación discursiva pone los límites hasta los cuales puede moverse un discurso (desde otra formación discursiva).

Benveniste propone que el estudio de la enunciación debe centrarse en tratar de definirla en el marco formal de su realización, viendo las manifestaciones individuales que actualizan dicha enunciación, mientras que para Foucault, el análisis (histórico) del discurso busca entender por qué un discurso ha sido dicho en un momento histórico específico y no en otro, es decir, cuáles han sido las circunstancias relevantes para encontrarlo ahí.

Por otro lado, en ¿Qué significa hablar? Economía de los intercambios lingüísticos (2008), Bourdieu habla del lenguaje como de un mecanismo formal cuyas capacidades son ilimitadas, como decía Foucault, pero también habla de él como de acción y poder. En este sentido, plantea que los intercambios lingüísticos implican relaciones de poder simbólico que actualizan aquellas relaciones de poder entre quienes participan en dichos intercambios (a diferencia de Benveniste y Bajtín, él habla de locutores como participantes de tales intercambios). De tal manera, Bourdieu ve al lenguaje como otro tipo de capital, capital lingüístico, en el que las relaciones de poder delimitan no sólo aquello que puede decirse frente a aquello que no puede decirse, como decía Foucault, sino que también delimitan el campo de lo que vale la pena escuchar o, en el caso de la literatura, de lo que vale la pena publicar y leer. 
Para Bourdieu, el capital lingüístico no es como se postula el carácter de la lengua, que es homogénea y legítima, sino la manera como la forma circula por un mercado en forma de discursos estilísticamente caracterizados, como usos individuales de la lengua, diferentes de aquello que se marca por las normas lingüísticas, o como actualizaciones individuales de la lengua nacional, en el sentido de Bajtín.

Bourdieu, de manera similar a Foucault y Benveniste, dice que las palabras a efectos de diccionario no existen, sino que sólo pueden encontrarse inmersas en situaciones específicas. Es decir, no se encuentran neutras en el uso sino que, como también decía Bajtín, se han cargado de valoraciones sociales y de la expresividad de quien las usa, de quien se las apropia y las hace suyas. También, en el sentido de Foucault, Bourdieu ve a los discursos como anfibios que pueden dispersarse desde un discurso de los dominantes a un discurso de los dominados (aunque esto genere malentendidos).

Una discusión importante planteada por Bourdieu tiene que ver con la lengua legítima, es decir, con aquella que ha sido planteada como homogénea para una comunidad también homogénea que toma a esa lengua como un tesoro que debe conservar. En este sentido, también la lengua participa de discursos hegemónicos, como decía Foucault, o de un discurso que, desde la gramática y la racionalización del uso de la lengua, pretende imponer un uso correcto de la lengua desde una posición dominante. En este sentido, una lengua se distingue de un dialecto porque la primera sí tiene el privilegio de poder ser impuesta de manera general sobre una comunidad, mientras que el segundo no, lo que permite que la comunicación y la producción económica se generen con esa lengua oficial y no con un dialecto. Esto, nuevamente retomando a Foucault, constituye un discurso sobre la lengua en relación con el Estado.

Para Bourdieu, la lengua legítima va ligada a la lengua estándar, que es un producto normalizado establecido como tal desde instituciones de unificación lingüística como las instituciones escolares, donde se enseñan los usos legítimos de la lengua, los usos neutros. Y, con la imposición de esa lengua sobre otras, se imponen también discursos de autoridad ${ }^{25}$.

\footnotetext{
${ }^{25}$ A este respecto, Cristina Rivera Garza (2018) retoma las palabras de Yásnaya Aguilar y dice: "la diferencia entre las lenguas indígenas y otras en las Américas es que las primeras se las arreglan para sobrevivir sin un Estado que las respalde- o incluso a pesar de tenerlo en contra- Son lenguas sin ejército.” Quizá valdría la pena
} 
Bourdieu también habla del papel del campo literario en la lucha por la autoridad lingüística, pues en este campo nuevamente se encuentran enfrentamientos entre usos lingüísticos dominantes y dominados. En este sentido, vuelve a retomar la idea de que no todos los discursos son dignos de ser escuchados o leídos, oficializados, no todos son discursos que sirven como ejemplos del buen uso de la lengua legítima (Bourdieu 2008, 42), de tal manera que ayudan a definirla.

A diferencia de Foucault, Bourdieu no habla de un discurso de autoridad como de una construcción que se encuentre en una posición jerárquica mayor respecto a otra, sino que habla de usos lingüísticos legítimos e ilegítimos, usos que se encuentran al margen de la norma lingüística que no los reconoce como lenguas, porque participan de un discurso sobre la gramática que la ve como homogénea y que, desde ahí, pretende fijar el valor de la lengua. Para Bourdieu, tanto importa la producción literaria en una lengua como la manera en que ésta se enseña para poder reconocer las repercusiones que la lengua legítima tiene en la vida social.

Según lo anterior, el spanglish, particularmente los discursos escritos en spanglish, pueden verse a partir de Bourdieu como discursos en los que se confrontan luchas entre usos legítimos de la lengua legítima y usos que, aún permitidos por la esfera hegemónica de la corrección literaria, no son reconocidos como legítimos, no son tomados como lengua, sino como dialectos, como usos que deben sufrir sanciones porque no responden a la norma (y una de esas sanciones será la falta de publicación, o la publicación por editoriales menos importantes o con mercados menores). El spanglish participa de un discurso según el cual la lengua reconocida es el inglés, pero permite la coexistencia, en un mismo enunciado, de la gramática de esta lengua con la gramática del español. En este sentido, el uso del spanglish no es un uso legítimo de la lengua, pero el hecho de que tenga literatura permite pensar que ciertos usos del spanglish pueden acceder a la escritura literaria como campo de lucha por la autoridad lingüística, en este caso, de ese mismo spanglish (Bourdieu 2008, 41). La literatura será un campo también de unificación de los distintos usos (escrituras) del spanglish, donde ciertos usos se verán, en el sentido de Foucault, jerarquizados a posiciones dominantes.

retomar el papel de las academias en relación con los estados-nación, pues al tratar de fijar la lengua participan de uno de los símbolos de dichos estados. 
Lo que Bourdieu permite ver en torno al spanglish, es cómo se trazan distintas relaciones de poder entre usos legítimos de la lengua y usos ilegítimos, que explican el hecho de que ciertos enunciados en spanglish puedan entrar en ese juego de fuerzas, por ejemplo, en el ámbito literario como ámbito de autoridad lingüística. En este sentido, un análisis del spanglish desde Bourdieu implica preguntarse qué significa que algo sea dicho en spanglish, qué significa hablar spanglish tomando en cuenta las relaciones de poder que sustentan la fuerza del capital lingüístico.

Según los autores expuestos anteriormente, los discursos en spanglish, como producciones que retoman dos gramáticas, pueden verse desde varios ángulos: son discursos que toman como soporte a la escritura para ser dichos, ya que pueden ser publicados, (como en el caso del novelista Junot Díaz o Giannina Braschi) o no (como Yesika Salgado) y que retoman la oralidad con la que surgió el spanglish pero la llevan a la escritura, en la que aparecen no sólo palabras y estructuras sintácticas o morfológicas de las dos lenguas, sino que también se presenta la pronunciación de cada palabra desde la lengua en la que se le toma. De tal forma, pueden encontrarse enunciados en los que una palabra en español se incluya con su pronunciación en español, aunque el resto del enunciado se encuentre en inglés.

Las producciones discursivas en spanglish son tales en tanto que implican un uso de la lengua en un momento y lugar específicos en la historia, por lo que son acontecimientos. La creación literaria en spanglish, como creación lingüística, es una de las formas de usar el conjunto de signos de la lengua en el soporte que requiere la escritura, pero es enunciativa en el sentido en que conlleva unidades concretas de la lengua que han sido dichas, como hechos del discurso. De acuerdo con Bajtín, podrían entonces verse como producciones en las que palabras neutras de dos lenguas se hacen propias al cargarse de nuevos sentidos y expresividades, una vez que aparecen en discursos específicos en donde no funcionan ya como palabras del español o del inglés.

Para Foucault, el inglés y el español, en tanto lenguas, coexisten, como la posibilidad de crear enunciados, en una misma formación discursiva. En este sentido, los enunciados en spanglish son acontecimientos históricos discursivos, pues dicen algo que no había sido 
dicho, permiten la coexistencia de gramáticas que no habían coexistido, pero también, en el sentido en que para Bajtín serían enunciados contestatarios, porque irrumpen en la historia.

Por tanto, investigar las producciones literarias en spanglish supone un acercamiento al lenguaje en uso, mediante la escritura, que puede abordarse a través del análisis del discurso. Dichas producciones literarias, en tanto que suponen la puesta en marcha de una maquinaria editorial específica, se sitúan en el campo cultural pero también en el político, porque las publicaciones forman parte del proceso de legitimación y homogeneización de la lengua. Así, un acercamiento a los procesos editoriales por los que atraviesan las publicaciones en spanglish también permite conocer cómo es que el spanglish es percibido, escrito, publicado y leído en Estados Unidos.

III. Te llamo pa'trás: manifestaciones del spanglish en las escrituras latinas

Desde los conceptos de enunciado, discurso, corpus y archivo, expuestos anteriormente a partir Foucault, en el presente apartado se expondrán algunas singularidades extraídas a partir de la conformación de un archivo sobre literatura en spanglish. Por esa razón, planteamos que en un mismo corpus-archivo, conformado por literatura de escritores latinos en Estados Unidos, pueden verse diferencias pero también singularidades, aunque los tipos de enunciados que conforman cada poema sean muy distintos. Por ejemplo, en su uso de la lengua se sigue hablando de comunidades de migrantes que han tenido que integrarse a una nueva nación, pero sin dejar por completo de lado su identidad latina. Este archivo, entonces, permite ver qué se ha dicho sobre el spanglish y cómo éste ha conformado distintos discursos, cómo distintos enunciados escritos en ambas lenguas se plantean como enunciados no reconocidos como usos estándar de ninguna de las dos gramáticas, tal y como señalaba Gloria Anzaldúa.

De acuerdo con lo anterior, el corpus retomará exclusivamente escrituras producidas por autores latinos en el presente siglo, que se encuentren escritas en spanglish, o que hablen sobre este contacto lingüístico en alguna de las dos lenguas (inglés y español) que lo 
conforman, aunque para llegar a ese último análisis, en el sentido histórico, es necesario antes conformar un archivo sobre literatura en spanglish que retome también a la literatura chicana, como una de las primeras expresiones literarias que retoman al inglés y al español.

\subsection{Hablar desde donde se habla: escritura en la liminalidad}

Como mencionamos anteriormente, el territorio al suroeste de Estados Unidos ha sido un espacio delimitado por distintos tipos de fronteras móviles a lo largo de su historia. Este territorio tenía una población hispanohablante de origen mexicano que, con los años y con los distintos cambios geopolíticos en el territorio, fue cambiando de lengua, adquiriendo otra cultura y relacionándose de manera distinta con el país al que antes pertenecía este espacio geográfico: México. Quizá uno de los eventos históricos más importantes ocurridos en este territorio, además de la firma del Tratado de Guadalupe (que permitió a Estados Unidos recorrer su frontera sur hacia donde se encuentra actualmente) fue el surgimiento del movimiento chicano, que buscaba mejores condiciones laborales para aquellos que trabajaban en el campo, mejores condiciones educativas para aquellos a quienes se les negaba el acceso a las escuelas por ser hispanohablantes, hijos de mexicanos o migrantes; en general, el movimiento chicano buscaba mejores condiciones de vida.

Este movimiento se caracterizó, en parte, por su legado artístico, conformado por poesía, murales, novelas, obras de teatro y otros materiales con los que los artistas chicanos buscaban mostrar sus problemáticas diarias como parte de una población no-blanca, campesina, hispanohablante, y que constituían una temática recurrente en sus distintas obras de arte.

Como menciona Jack D. Forbes en Aztecas del norte: the chicanos of Aztlán (1973), una característica importante de la comunidad chicana era que, en algún grado y a diferencia de otras poblaciones latinas, tenían descendencia indígena. En este mismo sentido, Debra A. Castillo (2008) hace mención a una diferencia notoria entre las mujeres chicanas y las mexicanas que participaban en coloquios sobre literatura de mujeres en los años setentas: las 
mujeres chicanas eran morenas, descendientes de migrantes o campesinos, generalmente pertenecientes a clases bajas (mientras que las mujeres mexicanas pertenecían a clases más altas y eran generalmente blancas). Esto también conformó en gran parte la literatura producida por estas mujeres, que resultó ser una literatura interseccional: ponía énfasis tanto en las opresiones que sufrían como mujeres como en aquellas que se debían a su condición de ser morenas, de descendencia indígena e hispanohablantes.

De lo anterior surge la pregunta sobre si estos temas eran los únicos que se abordaban en la literatura chicana e incluso, podría plantearse, sobre las maneras en que se abordaban. Para Gloria Anzaldúa, el uso mismo del lenguaje era una forma de mostrar cómo vivía siempre dividida por un muro impenetrable entre dos mundos, por lo que constantemente cambiaba entre la gramática del inglés y la del español:

To live in the borderlands means you

are neither hispana india negra española

ni gabacha, eres mestiza, mulata, half-breed

caught in the crossfire between camps

while carrying all five races on your back

not knowing which side to turn to, run from;

To live in the Borderlands means knowing that the india in you, betrayed for 500 years, is no longer speaking to you,

the mexicanas call you rajetas, that denying the Anglo inside you

is as bad as having denied the Indian or Black;

Cuando vives en la frontera

people walk through you, the wind steals your voice,

you're a burra, buey, scapegoat,

forerunner of a new race,

half and half-both woman and man, neither-a new gender

(Anzaldúa 1987, 194) 
Las problemáticas de la comunidad chicana y, más ampliamente, las de las comunidades latinas, han cambiado así como ha cambiado esa frontera entre México y Estados Unidos. En este sentido es importante pensar también sobre las particularidades de la literatura latina y chicana actuales, en contraste con aquellas literaturas de estas mismas comunidades producidas en el siglo pasado, para entender de qué manera entretejen con palabras las problemáticas del siglo presente.

El presente apartado tiene como finalidad ahondar en la historia de la literatura chicana para poder hablar un poco sobre sus particularidades, sobre los temas de los que se escribía y la manera en que se utilizaba el lenguaje, lo que permitirá luego contrastarla con la situación actual de la literatura chicana y latina en Estados Unidos.

\subsubsection{Los chicanos de Aztlán: si nos construyen muros, se los tiramos con palabras}

Como mencionamos antes, una de las manifestaciones artísticas más importantes del movimiento chicano fueron, sin duda, la poesía y el ensayo. Desde la poesía de Alurista hasta los escritos de Anzaldúa, que combinaban varios estilos, un común denominador de sus creaciones era su sentido político, pues criticaban en sus escritos tanto la identidad chicana, de una comunidad de migrantes mexicanos en contacto cercano con la cultura anglosajona, como el abandono de las tradiciones mexicanas y el uso del español, lengua que los chicanos iban dejando de lado, no sólo por la asimilación cultural sino por la falta de enseñanza de esta lengua en las escuelas y por la represión que las instituciones educativas estadounidenses ejercían sobre el uso de la lengua. Así, el espanglish en esta literatura aparece como una manera de reafirmar una identidad también lingüística que no es ya completamente mexicana, que no habla solamente español, pero que tampoco es estadounidense, y que en este sentido no habla únicamente inglés.

Aunque el inicio de la historia chicana se reconoce en 1848, para Ch. Tatum (1986) ese inicio puede rastrearse hasta mediados del siglo XVI, cuando el suroeste de Estados Unidos aún pertenecía a México, lo que hacía que las producciones literarias de la época 
fueran narrativas épicas, sobre las fundaciones de los distintos poblados, sobre religión o dramas populares, escritos por los pobladores hispanohablantes de dicha región geográfica. Así, para Tatum el primer teatro comunitario surgió en el suroeste de Estados Unidos hacia finales del siglo XVII, aunque también existen indicios de teatro profesional en estas mismas regiones.

Aún pocos años después del Tratado de Guadalupe, muchos hispanohablantes, que siguieron ocupando el entonces nuevo territorio de Estados Unidos, seguían identificándose como mexicanos, por lo que los primeros cuentos chicanos (algunos publicados en una antología titulada Mexican folk narrative from the Los Angeles area) retomaban leyendas populares sobre religión, demonios, héroes, fábulas, encantamientos y relatos didácticos, entre otros temas. Posteriormente surgieron crónicas sobre la ocupación española de México, narradas a través de personajes españoles imaginarios asombrados por la flora y fauna del territorio (estas historias fueron populares entre el siglo XVI y el siglo XIX).

Hasta esa época, no puede hablarse aún de la narrativa chicana como de una narrativa politizada que hablara de las situaciones que vivía la comunidad. Posteriormente comenzaron a surgir periódicos en la región que, editados en español, hablaban sobre la guerra texanomexicana, el Tratado de Guadalupe Hidalgo y el Tratado Gadsden, pues estos eventos habían producido grandes cambios dentro de las comunidades del suroeste. A partir de este momento, surge una necesidad dentro de la comunidad hispanohablante por defender la cultura y la identidad que les conformaba, por lo que entre 1848 y 1958 se publicaron alrededor de 400 obras, entre poesía y narrativa, en distintos periódicos. En este sentido, uno de los escritores quizá más reconocidos de la época fue Jorge Ulica, quien criticaba constantemente la asimilación de los mexicanos a la cultura angloparlante que se les imponía como una cultura superior, tanto en términos tecnológicos como culturales, por lo que muchos de sus escritos criticaban la manera en que los mexicanos hablaban inglés o cómo imitaban costumbres que no eran suyas (una de sus publicaciones se titula Por no hablar inglés no hay que hablar en pocho y otra Cómo hacer surprise parties). Sin embargo, no todas las publicaciones literarias en estos periódicos tenían que ver con esa crítica a la cultura que se les imponía, sino que muchos hablaban también sobre otros aspectos de la vida, narraban fábulas e historias sobre fantasmas, etcétera. En este mismo periodo se publicaron 
también varias novelas, aunque es importante mencionar que se encontraban escritas en inglés.

En 1856, el periódico El clamor público publicó un poema anónimo que, escrito en español, proponía una crítica al sistema de justicia estadounidense en el que los hispanohablantes del territorio no recibían los mismos tratos que los angloparlantes:

\author{
Allá en la Corte Suprema \\ donde reina la integridad \\ veo que no hay igualdad \\ por llevar otro sistema. \\ ¡Quién es el que no se queja \\ al mirar que el tribunal \\ no nos considera igual \\ dándole preferencia \\ a don fulano de tal!
}

(cit. por Tatum 1986, 73)

Hacia mediados del siglo XIX, con las problemáticas sociales y los cambios políticos de la región que afectaban a la comunidad hispanohablantes al suroeste de Estados Unidos, comenzaron a surgir obras que retomaban tanto esas problemáticas como otras: las guerras de Estados Unidos contra España y Alemania en las que muchos mexicanos participaron. También se escribía sobre la situación de la cultura mexicana frente a la cultura anglosajona que se les imponía.

Posteriormente, en 1979, se estrenó una de las obras de teatro más importantes de la literatura chicana, Zoot Suit de Luis Valdez, retomando nuevamente un tema bélico, la guerra de Vietnam, pero enfocándose en las distintas formas de violencia que los pachucos al norte de la frontera vivían, por ser mexicanos o hijos de mexicanos, por no ser estadounidenses, por no ser blancos. Esta obra fue luego adaptada como película, dirigida por el mismo autor, en 1981. Ambas versiones Valdez también escribió sobre temas como la huelga campesina 
que dio origen al movimiento chicano. En este mismo sentido, Max Martínez escribe The Adventures of the Chicano Kid and Other Stories en 1982, cuentos en los que retoma nuevamente la problemática de las culturas que se encuentran: la mexicana y la anglosajona, en este caso (Tatum 1986) ${ }^{26}$.

En la literatura del movimiento chicano, como muestran varios autores, el lenguaje juega un papel fundamental, por lo que muchas de las obras estaban escritas en inglés y en español simultáneamente, es decir, a diferencia de las primeras obras literarias chicanas, ubicadas en los siglos anteriores al movimiento chicano, que se escribían en inglés o en español y que, como se mencionó, incluso se mofaban sobre cómo los hispanohablantes utilizaban el inglés. La poesía de esta época se encuentra altamente politizada y rara vez deja de lado los problemas sociales de la comunidad, y que eran aquellos por los que comenzaron las manifestaciones del movimiento chicano. En este sentido, Alurista, poeta del movimiento chicano, escribe Mis ojos hinchados:

Mis ojos hinchados

flooded with lágrimas

de bronce

melting on the cheek bones

of my concern

razgos indígenas

the scars of history on my face

and the veins of my body

that aches

vomita sangre

y lloro libertad

I do not ask for freedom

I am freedom

no one

not even Yahweh

and his thunder

can pronounce

and on a stone

la ley del hombre esculpir

no puede

mi libertad

and the round tables

${ }^{26} \mathrm{Ch}$. Tatum (1986), como hemos venido mencionando, narra la historia de la literatura chicana desde antes de que la frontera norte de México se configurara como la conocemos actualmente. Pese a que el dato sobre la publicación de The Adventures of the Chicano Kid and Other Stories fue tomado de dicha obra, no encontramos la referencia completa por lo que sólo citamos el año del libro. 
of ice cream

hot dog

meat ball lovers meet

to rap

and rap

and I hunger

y mi boca está seca

y el agua cristalina

y la verdad

transparent

in a jarro

is never poured

dist gathers on the shoulders

of dignitaries

y de dignidad

no saben nada

muertos en el polvo

they bite the earth

and return

to dust

(Alurista 2002, 205)

De la misma manera en que Alurista conjuga el español y el inglés para la creación de su poesía, retomando la manera en la que hablaban los chicanos y llevándola a la creación, otros autores como Inés Hernández Tovar escribe el poema Untitled, aunque en él no habla sobre el movimiento chicano sino sobre su relación con un "bato":

So you say to yourself

"She need to know that

I'm really angry"

So you sulk

And smoke

And stalk around

But you are hurt inside,

I mean bien sentido

And you want my arms

Around you

And later on, you'll

Even say "I love you" 
And the same damned

Confianza

That says you're right

Is the same that tells

You I'll come back

Pues, ¿sabes qué, bato?

Not this time,

This time the ice froze over

Y aunque el miedo me resfría,

This time, I won't go

(cit. por Tatum 1986, 230)

Aunque los poemas anteriores se escriben en inglés y español, no hablan particularmente sobre la lengua, como sí lo hace Gloria Anzaldúa en How to tame a wild tongue:

I remember being caught speaking Spanish at recess- that was good for three licks on the knuckles with a sharp ruler. I remember being sent to the corner of the classroom for "talking back" to the Anglo teacher when all I was trying to do was tell her how to pronounce my name. "If you want to be American, speak 'American'. If you don't like it, go back to Mexico where you belong."

"I want you to speak English. Pa'hallar buen trabajo tienes que saber hablar el inglés bien. Qué vale toda tu educación si todavía hablas inglés con un 'accent'", my mother would say, mortified that I spoke English like a Mexican. At Pan American University, I, and all Chicano students, were requiered to take two speech classes. Their purpose: to get rid of our accents.

Attacks on one's form of expression with the intent to censor are a violation to the First Amendment. El Anglo con cara de inocente nos arrancó la lengua. Wild tongues can't be tamed, they can only be cut out

(Anzaldúa 1987, 53-54)

A diferencia de otros autores chicanos, Anzaldúa hace una crítica explícita a la manera en que era percibida la comunidad chicana en tanto comunidad hispanohablante en territorio estadounidense. Desde ahí, para ella, hablar español chicano o espanglish, moverse constantemente entre las dos lenguas, representaba una manera de cruzar simbólicamente la 
frontera entre México y Estados Unidos, con el lenguaje, deshaciéndose de los muros que separan a ambos países. En este sentido, otro de sus poemas, El otro México, habla sobre esa frontera:

1,950 mile-long open wound

Dividing a pueblo, a culture, running down the lenght of my body, staking fence rods in my flesh, splits me splits me me raja me raja This is my home this thin edge of barbwire

But the skin of the earth is seamless.

The sea cannot be fenced.

el mar does not stop at the borders.

To show the white man what she thought of his

arrogance,

Yemayá blew that wire fence down.

This land was Mexican once, was Indian always

and is

and will be again

Yo soy un puente tendido

del puente gabacho al del mojado.

lo pasado me estira pa'tras

y lo presente pa'delante

que la Virgen de Guadalupe me cuide

Ay ay ay, soy mexicana de este lado

(Anzaldúa 1987, 1-3)

En este poema, Anzaldúa vuelve a escribir en ambas lenguas, comenzando en una y terminando en otra. Al final del poema hace un juego lingüístico con la sonoridad de ambas lenguas, haciendo una alusión sonora con ay, ay, ay al pronombre en inglés, $I$, retomando de nuevo las dos gramáticas en su escritura.

Como menciona Debra A. Castillo en Chicana feminist criticism (2008), Gloria Anzaldúa fue una de las primeras escritoras chicanas en poner sobre la mesa la multiplicidad 
de los temas que la oprimían como mujer chicana: la raza, la clase y el género siendo hija de varias generaciones de mexicanos en Texas. En la literatura de Anzaldúa se pueden encontrar varios de los temas frecuentes en la narrativa chicana, como el mito de Aztlán, esa tierra al norte que los chicanos asumieron como su origen y como el nombre de aquel territorio al suroeste de Estados Unidos en el que viven. Para Gómez-Peña, el espanglish en la literatura de esta generación (la de Anzaldúa y Luis Valdez) aparecía como el lenguaje de la intimidad, la primera casa, la memoria lejana, la mitología, los sueños y la brujería $(2006,256)$.

De la misma manera que Anzaldúa, J. H. Zentella escribe un cuento, en The eve of the macho, publicado en 1980, en el que habla sobre hablar español, como chicano, aunque escribe en inglés:

There he was. Speaking his own private language, a language I have never been able to grasp... a language learned in centuries of ruthless, rootless poverty and defeat. The language of the weak-er, meek- A language that perhaps my ancestors once spoke but didn't let us learn. The language of the anonymous heroes.

(Zentella 1980, 42)

Otro tema frecuente en la narrativa chicana es la comida, como menciona Jacqueline Zeff en "What doesn't kill you makes you fat": the language of food in latina literature (2008). Es importante señalar que este ensayo analiza también el lenguaje de la comida en la literatura de otras comunidades latinas, no solamente en la de la comunidad chicana. El tema de la comida aparece en la obra de Anzaldúa, pero también en la obra artística de GómezPeña, quien en su performance Instant identity ritual toma una botella de salsa de un trago. La comida y los nombres de los platillos, que permanecen en español aunque se escriba en inglés, son un fuerte símbolo cultural. En este sentido, Anzaldúa dice:

For me food and certain smells are tied to my identity, to my homeland. Woodsmoke curling up to an immense blue sky; woodsmoke perfuming my grandmother's clothes, her skin. (...) Homemade white chees sizzling in a pan, melted 
inside a folded tortilla. My sister Hilda's hot, spicy menudo, chile colorado making it deep red, pieces of panza and hominy floating on top.

Un tema que retoman varios autores chicanos, como Gloria Anzaldúa, Cherríe Moraga y Jack D. Forbes, es la de la identidad racial, pues se consideran mestizos y escriben sobre ello:

MESTIZO: bastard offspring

of Spanish Conquest

conceived not of love

but through wanton ruthless rape of beautiful

Bronze mother/fathered by cruel \& vicious European animal...

Spaniard

Cast away the devil

Placed over dark brown eyes

See the beauty that is yours!

(cit. por Forbes 1973, 298)

En este mismo sentido, Gómez-Peña escribe sobre su identidad contradictoria, compuesta, múltiple, en Brownout Pt. 2:

Dear audience:

Tonight from my multiple repertoires of hybrid personas, I have chosen to come as the embodied psyche of an existentialist mojado

$\&$ it's quite a challenge my dear friends

for I've been stripped by airport security of all my robo-baroque paraphernalia my ethno-technobilia ye-ye 
which means, no more hand-made lowrider prosthetics

no mariachi robotic bodywear

no cheesey fog machines

no hanging dead chickens, nothing

not even a voice-effect processor

to help me get rid of my accent

just one costume,

$\&$ a bit of make-up

to protect myself

o sea, back to the basics of performance

It's Chicano minimalism

a contradiction in terms

but hell, I am a walking contradiction

$\&$ so are you...

(Gómez-Peña 2003)

Una parte importante de la obra de Gómez-Peña trata sobre el proceso de migración a través de la frontera México-Estados Unidos, una frontera que los mismos migrantes cruzan de ida y de regreso constantemente durante los años ochenta, antes de la implementación de ciertos mecanismos de seguridad y políticas migratorias que dificultaban ese cruce y, sobre todo, la estadía de los migrantes en Estados Unidos por periodos largos de tiempo (esas políticas, de hecho, se han endurecido con los años a tal grado que el número de migrantes, según el Instituto Nacional de Migración en 2014, era casi el mismo número que el de deportados).

Valdría la pena referirnos a una diferencia entre las primeras generaciones de mexicoamericanos que se identificaban como chicanos y otras generaciones de chicanos, pues si retomamos la historia narrada anteriormente, los movimientos migratorios desde México hacia Estados Unidos han sido múltiples y se han dado a lo largo de toda la historia de la frontera norte. Sin embargo, antes de que esa frontera se instituyera como tal, habitaban en el territorio norte del entonces México, hispanohablantes que constituyeron la primera generación de chicanos, participando del cambio de nacionalidad, lengua y cultura, como consecuencia del cambio de frontera. Podría decirse, entonces, que las generaciones posteriores de chicanos (a las que pertenece Gloria Anzaldúa) ya no se relacionaron de la misma forma con ese cambio de frontera, aunque igualmente se vieran en la liminalidad de pertenecer al mismo tiempo a la cultura mexicana, anglosajona y, de ahí, a la chicana. Es 
importante mencionar que durante los años posteriores al cambio de frontera se dieron varias olas importantes de migración, entre las que cabe destacar la ocurrida con el Programa Bracero a partir de 1942. Gómez-Peña, a diferencia de esos chicanos que ya se encontraban en el suroeste de Estados Unidos en 1848, o de aquellos que nacieron en Estados Unidos como hijos de aquellos primeros chicanos, incluso a diferencia de otros chicanos hijos de migrantes, nació en México y migró hacia Estados Unidos, por lo que su experiencia con la frontera y con lo que él llama proceso de chicanización, es otra, similar a la de otros escritores migrantes. Este proceso es cuestionado en su poesía, de la que el siguiente texto sirve de ejemplo:

¿Cómo fundamentar y articular mis múltiples repertorios de identidad en un país que ni siquiera me consideraba un ciudadano? ¿Cuáles son los factores cruciales que determinan el grado de chicanización? (...)

Hoy, después de 24 años de cruzar esa maldita frontera en ambas direcciones; a pie, en auto y en avión, cuando escribo este texto me pregunto si todavía importa cuándo sucedió mi conversión. En este momento me doy cuenta de que el espacio entre mi remoto pasado mexicano y mi futuro chicano es inmenso y que mi identidad puede zigzaguear libremente entre el uno y el otro. Finalmente, fueron mi arte y mi literatura los que me otorgaron la plena ciudadanía que ambos países me habían negado. A través de mi obra, inventé mi propio país conceptual.

(Gómez-Peña 2006, 231)

En el mismo sentido, dice él, sobre usar el inglés y el español:

I dreamt in Spanish that one day I decided to never perform in English again. A partir de ese momento, me dediqué a presentar mis ideas y mi arte estrictamente en español y sólo para públicos estadounidenses atónitos que no entendían nada. Mi español se hizo cada vez más retórico y complicado hasta el punto en que perdí todo contacto con mi público. A pesar de los ataques de los críticos racistas, me empeciné en hablar español. Entonces, mis colaboradores se molestaron y empezaron a abandonarme. Eventualmente me quedé completamente solo, hablando en español, 
ante fantasmas conceptuales angloparlantes. Afortunadamente I woke up and I was able to perform in English again. I wrote in my diary: "Dreams tend to be much more radical than 'reality'. That's why they are much closer to art than to life".

(Gómez-Peña 2006, 223)

Quizá podamos decir también que los distintos procesos migratorios y fronterizos (pensando en una frontera cultural) se ven reflejados tanto en el uso del lenguaje que hacen los distintos escritores mencionados, desde el tono mismo de su escritura, pues mientras para unos la añoranza de lo mexicano podría leerse en un tono nostálgico, para otros, como Gómez-Peña, es más bien algo que puede ponerse a crítica en un sentido más cercano a la burla. Así, cuando él escribe sobre cómo es más fácil transformar la realidad a partir del arte (y de los sueños), o cuando plantea su identidad contradictoria, se burla de los distintos procesos por los que ha pasado como mexicano en Estados Unidos, mientras que Anzaldúa o Alurista, como partícipes del movimiento chicano, narran más desde los no-recuerdos (esos relatos sobre la frontera y la migración que les fueron contados quizá por sus padres, pero que no vivieron) y que por tanto no pueden criticar en el mismo tono.

Entonces, la literatura de Gómez-Peña, como la de Gloria Anzaldúa y otros autores chicanos, retoma al espanglish y, en su caso, al inglés o al español, como lenguas madrastras, lenguas que se toman para la creación de un nuevo país conceptual que, en la liminalidad, ya no es ni Estados Unidos ni México, pero que participa de los procesos migratorios que se mueven entre estos dos países. Así, tanto aquellas generaciones de chicanos que aprendieron inglés como lengua materna, siendo hijos de generaciones anteriores de hispanohablantes en Estados Unidos, como aquellos otros chicanos que se han asumido como tales a partir de sus experiencias migratorias como hispanohablantes nacidos en México, tomar una lengua para la escritura implica desterritorializarla, politizarla y colectivizarla para la creación de una literatura menor: estos escritores chicanos retoman en su escritura el español que aprendieron como lengua materna en un contexto donde les ha sido impuesto el inglés, como lengua madrastra, lo que ya es un acto político en un país en el que no se reconoce el uso del español, y además generan con esa literatura un sentimiento de pertenencia a una colectividad, a partir de la exclusión de ésta dentro del contexto angloparlante. Así como dice Angela de Hoyos en entrevista con Javier Vázquez-Castro: 
[...] la literatura es un escape. Me gusta transmitir ese mensaje de rebelión, de protesta, pues me parece que así como siento yo, sienten otras mujeres (...). Y la palabra escrita interesa por el poder que tiene Así, por medio de la expresión escrita se puede llegar a muchos y tener una influencia en muchos, para aclarar algo, discutirlo, para que se den cuenta de la realidad.

(Vázquez-Castro 1979, 21)

\subsubsection{Otras literaturas chicanas}

Por otro lado, dentro de las creaciones literarias más recientes de la comunidad chicana, podemos encontrar las mismas problemáticas que aparecían en la literatura de Gloria Anzaldúa, por ejemplo, en la poesía hablada (spoken word) y escrita de Yosimar Reyes, escritor que migró muy chico desde México a Estados Unidos, cuya obra ya puede situarse en el siglo XXI, a diferencia de los escritores anteriores, y que igualmente escribe en espanglish sobre las diferentes problemáticas que le atraviesan, no solamente como latino, chicano, en un país anglosajón, sino como "joto", como él se llama, inmerso en una sociedad que lo rechaza. En este sentido es que escribe Pride:

I am more than body

Beyond the rainbow flags and free condoms

The celebration of me is not found in parades

In a sea of half-naked men dancing to techno

The celebration for my spirit

Is not found in wet underwear contests

Random hook-ups

Over-sexualized drama

Or STDs

More than Dick I often think of spirit

And the fact that I've been broken

Through systems that keep me blind to my own self-actualization

Prevent me from seeing that I am Two-Spirit 
Como sacred ceremonias

Mi cuerpo es elemento

Something powerful

Algo that goes beyond the flesh

And is manifested through these poems

I am not Gay

Yo soy voz del más allá

Bendición de Ometeolt

Las dos energías

Something that cannot be described through a simple three- Letter word Like GAY

(Reyes 2018b)

En el mismo sentido en que Yosimar Reyes escribe sobre su experiencia como hombre homosexual, Gloria Anzaldúa y Cherríe Moraga escribían sobre ser lesbianas en la comunidad chicana. La identidad sexual, pues, ha sido un tema recurrente en la literatura de estos grupos que, como mencionábamos, ponen las luchas sociales sobre la mesa de su escritura.

La poesía de Yosimar Reyes, igualmente, retoma ciertos aspectos sobre la vida de la comunidad latina en Estados Unidos y habla sobre ellos en spanglish, mezclando frases y estructuras de dos lenguas, inglés y español, para su creación poética. En su poesía pueden encontrarse algunas referencias a la cultura mexica ("bendición de Ometéotl”), referencias que también aparecen frecuentemente tanto en la literatura como en el arte chicano. Reyes se posiciona como chicano, homosexual, y desde ahí escribe, retomando el espanglish no para hablar de él, sino para narrar sus experiencias, en el sentido de Anzaldúa, de alguien cruzado por varias fronteras.

En otras creaciones literarias, escritas también por latinos, podemos encontrar que el spanglish se utiliza no sólo para narrar experiencias similares a las de Anzaldúa y Reyes, sino para hablar sólo del lenguaje, en el mismo sentido quizá en que Anzaldúa hablaba de terrorismo lingüístico. Podemos, entonces, hablar de un primer tipo de literatura en espanglish que retoma estructuras y palabras de ambas lenguas, es decir, del inglés y del español, para abordar temas de distintas naturalezas, temas que sí atañen a sus comunidades 
pero que no necesariamente se concentran en hablar sobre el lenguaje, ni desde una ni otra lengua, como sí ocurre en otros casos de los que hablaremos a continuación.

\subsection{Hablar de lo que habla: ¿es posible un metaspanglish?}

Una de las características de la comunidad latina en Estados Unidos es su heterogeneidad: se conforma, como grupo, por personas que migraron hace años, personas que migraron muy chicas y aprendieron a hablar inglés, migrantes de reciente llegada que sólo hablan español, migrantes que no hablan español ni inglés, sino alguna lengua indígena latinoamericana, hijos y nietos de migrantes, personas que no conocieron el país de sus padres pero que hablan su lengua en distintos grados, personas ilegales y personas cuyo estatus migratorio les permite acceder a trabajo y educación. En este mismo sentido, las experiencias migratorias de cada grupo y, en particular, de cada persona, pueden ser muy distintas. Tanto existen migrantes en Estados Unidos que llegaron cruzando el Río Bravo como existen otros que llegaron en balsa o mediante el Programa Bracero, otros llegaron huyendo de las guerrillas de Latinoamérica, otros buscando diferentes objetivos, de manera que la relación que cada migrante tiene con su país de origen es distinta, como lo serán también las referencias que les transmitan a sus hijos sobre dichos países, lo que aprendan sobre ellos, y la manera en que se enfrenten a la cultura anglosajona.

De tal manera, la migración y la escritura en dos lenguas no es única dentro de la comunidad chicana, sino que aparece también dentro de otras comunidades latinas en Estados Unidos, como la puertorriqueña, la dominicana, la salvadoreña o la cubana, cuyos procesos migratorios y sus relaciones con la historia del territorio es distinta a la de la comunidad chicana. Desde el final del siglo XX, hacia inicios del siglo XXI, tuvo lugar un gran movimiento migratorio de escritores desde Latinoamérica. Algunos de estos escritores permanecieron en Estados Unidos, como menciona Cristina Rivera Garza, gracias al surgimiento de programas de escritura creativa en español (2018). Sin embargo la comunidad de escritores latinos se conforma también por escritores que nacieron como hijos de migrantes en ese país y por escritores que migraron bajo otras condiciones distintas a la 
búsqueda de programas académicos temporales. Podemos decir, entonces, que también es una comunidad heterogénea, en la que la migración aparece de maneras distintas.

Una de las escritoras latinas más importantes en Estados Unidos, dentro del siglo pasado, fue Giannina Braschi, quien de manera distinta a los escritores de la comunidad chicana, pero en el mismo sentido, escribió una novela titulada Yo-Yo Boing!, en la que cambia indistintamente entre el inglés y el español para narrar una historia, compuesta casi en su totalidad con diálogos, sobre distintos temas que atañen a la comunidad puertorriqueña. Esta novela, escrita en 1998, fue una de las más importantes publicadas por una escritora de la comunidad latina, precisamente por la alternancia y la mezcla de código con la que mostraba su habilidad para escribir en los dos idiomas:

-Si tú dices: Nunca. Oíste. No estoy enamorada. Yo soy un eco. Y el eco responde: Estoy enamorada. Estoy enamorada. Te amo. Te amo.

-It's torture to have to hear the opposite of what I negate. I say: I don't love you.

-I say: Love you. Love you.

-It breaks a person spirit. Don't you think?

-You think. You think.

-So I always have to hear you back-talk.

-It's your own voice contradicting you.

-No estoy enamorada.

-Estoy enamorada. Estoy enamorada. Te amo. Te amo.

-It's true. Eco is an original. She copies Narcissus' last words but projects a new meaning.

(Braschi 2011, 75)

Así, una escritora como Denice Frohman, hija de puertorriqueños pero nacida en Nueva York, refleja en sus poemas la manera en que ella aprendió español con su madre quien, a su vez, trataba de aprender inglés pero lo hablaba con acento hispanohablante. Esta problemática es la que ilustra en su poema Accents:

My mom holds her accent like a shotgun, with two good hands. 
Her tongue, all brass knuckle

slipping in between her lips

her hips, all laughter and wind cap.

She speaks a sanchocho of Spanish and English,

pushing up against one another,

in rapid fire

There is no telling my mama to be "quiet",

she don't know "quiet"

Her voice is one size better fit all

and you best not tell her to hush,

she waited too many years for her voice to arrive

to be told it needed housekeeping.

English sits in her mouth remixed

so "strawberry" becomes "eh-strawbeddy"

and "cookie" becomes "eh-cookie"

and kitchen, kay chain and chicken all sound the same

(Frohman 2013)

Algo recurrente en la literatura de ciertos escritores latinos, como en el caso anterior de Denice Frohamn, es hablar sobre el spanglish, o sobre la relación entre el inglés y el español con la que crecieron ellos o con la que se encontraron sus padres, pero no haciendo uso de estructuras en ambas lenguas, sino en una sola lengua, retomando palabras de la otra o la pronunciación de ciertos sonidos, como puede verse en el poema anterior, contrario a lo que hacía Yosimar Reyes, quien a partir de la alternancia y la mezcla de código, conjuntaba ambas lenguas en un mismo poema. Sin embargo, Denice Frohamn, en este poema y en otros como Abuela y Borders, ya no hace esto, sino que parte del inglés para hablar del español o, en su caso, del contacto entre ambas lenguas.

En este mismo sentido, Junot Díaz, escritor de República Dominicana, escribe en inglés, con algunas frases en español, sobre su experiencia como latino que migró a una corta edad hacia Estados Unidos. En los cuentos que compila en This is how you lose her (2012), habla, entre otros temas, de cómo los padres de su personaje principal, Junior, fueron migrantes, hispanohablantes, que se enfrentaron a una nueva forma de vida y a una nueva 
lengua que trataron de aprender, con dificultades, mientras él y su hermano la aprendieron más fácilmente. Una temática recurrente entre esos cuentos es también la creación y la percepción de la masculinidad latina a través de sus personajes hombres, desde la manera en que éstos se relacionan con los personajes femeninos.

\section{Invierno}

None of you are ready for guests, Papi said. Look at this house. Look at your children. Me da vergüenza to see them slouching around like that.

(Díaz 2012, 148)

\section{Miss Lora}

\section{I.}

Years later you would wonder if it hadn't been for your brother would you have done it? You remember how all the other guys had hated on her- how skinny she was, no culo, no titis, como un palito but your brother didn't care. I'd fuck her.

(Díaz 2012, 157)

Es interesante mencionar que las novelas y cuentos de Junot Díaz han sido traducidas al español pues, como mencionamos, están escritas casi totalmente en inglés, pese a que los ejemplos anteriores muestran casos en los que sí aparecen inglés y español reunidos en un mismo enunciado.

Quizá, en este sentido en que la escritura sobre las experiencias latinas no necesariamente conjunta dos lenguas en toda su estructura, sino en algunas ocasiones específicas, podamos pensar que "spanglish" no es una palabra que hace referencia únicamente a la mezcla lingüística entre inglés y español, sino que también refiere a la mezcla cultural, a la posición de los latinos en Estados Unidos como participantes de dos culturas, de aquella que, hayan vivido o no en su país de origen, los conforman, pero que también se ve confrontada a la cultura estadounidense que se les impone como una cultura de lo mainstream. Al respecto, Ed Morales escribe Living in Spanglish (2002), un ensayo en el que hace referencia a esa forma de vida de las distintas comunidades latinas. En dicho ensayo, 
hace hincapié en que, aunque cada comunidad es distinta, pues cada una viene de países diferentes, distanciados geográficamente en muchos casos, comparten ciertos aspectos que les permiten reconocerse en el spanglish, no sólo como lenguaje, sino como cultura. Es decir, por muy distintas que sean dichas comunidades, comparten una cultura del spanglish (Morales 2002, 116).

En este último sentido, es interesante ver también que ciertas producciones literarias en spanglish no retoman la mezcla y la alternancia de código para hablar de esas experiencias compartidas como comunidad latina, sino que lo hacen a partir de una única lengua, lo que da lugar a una escritura que puede traducirse hacia la otra lengua, aunque aparezcan rasgos de ambas lenguas. En otras obras, también de escritores latinos, podemos encontrar casos similares, en los que predomina la gramática de una lengua o no se retoma en absoluto alguna de las dos, pero que de cualquier manera hablan sobre las experiencias de la comunidad latina, sobre el contacto entre lenguas o específicamente sobre el spanglish.

\subsection{Hablar después de lo que habla: postspanglish}

Como mencionábamos en el apartado anterior, la comunidad latina en Estados Unidos es una comunidad heterogénea, también por su conocimiento de las dos lenguas con las que están en contacto: el inglés y el español. Las generaciones recientes, quizá no tendrán el mismo contacto con el español que tuvieron sus padres, quizá algunos ni siquiera aprendan a hablarlo aunque lo escuchen en el entorno familiar.

El caso de Melissa Lozada-Oliva y su escritura ilustra lo anterior. En uno de sus poemas, My Spanish, habla de su contacto con el español y de la manera en que ella puede hablarlo, ya no como sus padres lo hablaban, olvidando ciertas estructuras y palabras. Este poema está totalmente escrito en inglés, aunque luego ella misma lo tradujo a su versión en español. 


\section{Mi español ${ }^{27}$}

Si me preguntas qué tan fluido es mi español yo te diré:

mi español es la comezón de un brazo amputado:

busca palabras y sólo encuentra aire

Mi español es mi tercera fiesta de cumpleaños:

la mitad la tengo en mi memoria, la otra mitad es una fotografía en el refrigerador,

es lo que mi familia me ha dicho

Si me preguntas si mi español es fluido, te diré que mi español es un rompecabezas olvidado bajo la lluvia:

muy mojado como para hacer que sus piezas embonen y entonces sea igual a la foto de la caja

Te diré: mi español son adjetivos posesivos,

Son nombres propios que visten en perlas y brazaletes

Es el ¿sigues despierto?

Es el hay mucho que hacer hoy

Mi español está en mi currículum como una habilidad

Mi español está en mi cepillo de dientes como una marca roja de mis labios

Mi español soy yo, calcando mis dedos en cada letra donde pueden caber

Mi español es la verdadera historia del divorcio de mis padres, caótico, roto y otra cosa que tuve que elegir para recordarlo correctamente

Mi español se pregunta cuándo mis padres serán ciudadanos americanos que me pregunten si aún soy blanca

Si me preguntas qué tan fluido es mi español, te contaré la historia de cómo mis padres se conocieron en la clase de inglés, cuando entrenaban sus bocas para decir "te amo" en un idioma diferente , "te odio" con la boca cerrada

Te diré cómo el acento de mi padre lo hace sonar como zoro cómo mi madre intentó amarrar su lengua a un poste con la cadena del idioma inglés Te diré que su lengua siempre volvía terca hacia el idioma del que siempre estuvo enamorada, incluso cuando quería tomarla, siempre volvía

(Lozada-Oliva 2017)

\footnotetext{
27 Transcripción del poema a partir de su versión en video.
} 


\section{My Spanish}

If you ask me if I am fluent in Spanish I will tell you

My Spanish is an itchy phantom limb: reaching for a word and only finding air

My Spanish is my third birthday party: half of it is memory, and the other half is a photograph on the fridge is what my family has told me

If you ask me if I am fluent I will tell you that

My Spanish is a puzzle left in the rain

Too soggy to make its parts fit so that it can look just like the picture on the box.

I will tell you that

My Spanish is possessive adjectives.

It is proper nouns dressed in pearls and bracelets.

It is are you up yet. It is there is a lot to do today

My Spanish is on my resume as a skill.

My Spanish is on his favorite shirt in red mouth marks

If you ask me I will tell you

My Spanish is hungrier than it was before.

My Spanish reaches for words at the top of a shelf without a stepping stool

is hit in the head with all of the old words that have been hiding up there

My Spanish is me, tracing my fingers along every letter they were able to fit in

My Spanish is the real story of my parent's divorce

Chaotic, broken and something I have to choose to remember correctly

My Spanish is wondering when my parents will be American

asking me if I'm white yet

If you ask me if I am fluent in Spanish I will try to tell you the story

of how my parents met in an ESL class

How it was when they trained their mouths to say

I love you in a different language, I hate you with their mouths shut

I will tell you how my father's accent makes him sound like Zoro

how my mother tried to tie her tongue to a post with an English language leash

I will tell you that the tongue always ran stubbornly back to the language it had always

been in love with

Even when she tried to tame it

it always turned loose

(Lozada-Oliva 2015) 
Como mencionamos anteriormente, existen obras de escritores latinos que hablan sobre el contacto entre lenguas y culturas pero no a partir del spanglish, sino tomando sólo una de las lenguas que lo conforman. Esto último es lo que ha permitido la traducción de ciertas obras en las que si bien es posible leer ambas lenguas, la predominante es sólo una de ellas. Sin embargo, es interesante notar una diferencia entre aquellos autores que utilizan el spanglish para hablar del spanglish (en el sentido de la lengua o la cultura, o de la lengua como parte de la cultura) y aquellos que pueden hablar sobre esto pero sin acercarse al spanglish. Lo anterior puede notarse en la poesía de Melissa Lozada- Olivas, en contraste con la escritura de Junot Díaz, quien quizá puede ubicarse en el umbral entre estos dos casos, pues escribe predominantemente en inglés, no necesariamente sobre la lengua pero sí sobre sus experiencias como latino, retomando otra vez aquella idea de Ed Morales sobre vivir en spanglish.

La poesía de Melissa Lozada-Olivas muestra un cambio muy radical respecto a lo que era la creación literaria del movimiento chicano. Mientras aquella literatura se preocupaba por mantener la lengua, la cultura, las tradiciones, etcétera, ésta nueva poesía habla de cómo esa identidad lingüística se va difuminando en los escritores, aunque la cultura latina y la memoria de esa identidad resuenen en cada palabra.

Entonces, la creación literaria de los escritores latinos no se limita al uso del spanglish: pueden seguir abordándose ciertos temas desde una búsqueda por la identidad latina aunque ya no se retome esto en la estructura misma del lenguaje. De la misma manera, podemos encontrar ciertas creaciones en spanglish que se mueven hacia otros estilos, hacia otras formas de escritura, que pueden o no reconocerse como literatura, pero que ya no se quedan en la obra-libro, como en el caso del spoken word y de las canciones que sí retoman ambas lenguas.

El spanglish en la literatura latina aparece de diversas formas, su uso se ha movido hacia nuevos horizontes, enfrentándose a nuevas fronteras, recuperando distintas conexiones con el inglés y con el español, lenguas que siguen estando presentes en estas creaciones literarias como un eco constante. Entre el barullo de todas las lenguas que resuenan en las literaturas menores es necesario hacer silencio para escuchar esas otras voces. Ahí es donde 
una construcción como te llamo pa'trás grita ambas lenguas: se dice en español, pero tiene la estructura sintáctica del inglés. Es spanglish, como esas literaturas latinas en las que el uso de una lengua sirve como megáfono para la otra.

\section{Conclusiones}

En este último punto, retomaremos las problemáticas expuestas anteriormente a manera de cartografía, tratando de situar con palabras escritas, visuales, aquello que hemos dicho para trazar las líneas que nos permitan decir ahora en dónde se encuentra la literatura en spanglish, o hacia dónde se mueve. Esta cartografía hecha de palabras no es inmóvil, pues retomará aquello dicho antes, leerá las líneas de fuga trazadas desde el lenguaje, tratará de responder a la pregunta: ¿qué significa escribir spanglish?

Hemos dicho, hasta ahora, que la lengua se instituye como un dispositivo de poder. En este sentido hablar spanglish implica un uso de dos sistemas lingüísticos, el del inglés y el del español, ahí donde las categorías lingüísticas son políticas.

Como decíamos, no existe idioma puro, por lo que ese uso del lenguaje será múltiple: resuenan en el spanglish todos los usos del sistema lingüístico del inglés que hagan sus hablantes, y al mismo tiempo todos aquellos usos del sistema lingüístico del español, ambos en sus múltiples formas. Decimos, luego, que si ya utilizar la lengua tiene implicaciones políticas, escribirla es también una forma de retomar aquellos campos que han sido dispuestos para las lenguas mayores con un uso menor del lenguaje; escribir spanglish es, pues, utilizar una lengua impuesta, tomarla como madrastra para la creación de una literatura menor. Es ahí donde todo es político, donde el uso de la lengua es colectivo, donde los lenguajes se desterritorializan. En este sentido, una literatura en spanglish es, quizá, una forma de desterritorializar las herramientas del amo para así desmontar la casa del amo. Si recordamos nuevamente el concepto de lenguas ch'ixi, de Silvia Rivera Cusicanqui, decimos entonces que escribir en spanglish es utilizar una lengua para demoler ese contexto en el que 
surge: el spanglish es un lenguaje que parte de dos lenguas, tiene una escritura y tiene literatura.

Desde la literatura chicana podemos trazar tres manifestaciones del spanglish en la literatura latina escrita en Estados Unidos: primero, partiendo de aquella zona liminal que es la frontera, no sólo geopolítica sino también simbólica, en la que surge el movimiento chicano y la literatura chicana, el spanglish aparece como una forma de denuncia a partir del lenguaje, retomando los sistemas lingüísticos del inglés y del español para la creación literaria en torno a distintos temas; luego, decimos que el spanglish aparece en otra literatura sólo cuando se escribe sobre situaciones concretas ligadas a las experiencias de la comunidad latina en Estados Unidos (aparece, pues, como una forma de recuperar esa memoria colectiva); y, finalmente, decimos que el spanglish aparece para hablar del spanglish, de las experiencias de la comunidad latina, pero ya sin hacer uso de las dos lenguas que lo conformaban.

El inglés y el español aparecen, entonces, como lenguas madrastras en el spanglish, para permitir la creación de una literatura menor, de una literatura que se traza a partir de la colonización, de los movimientos políticos, de las crisis migratorias. Esta literatura surge a partir de esas distintas crisis y las pone en palabras escritas, oralizadas, las grita en el spoken word, las piensa sí a partir de la escritura pero para salirse de ella, para llegar más allá del libro, donde las páginas ya no son suficientes para enmarcar todas las problemáticas políticas que las hacen surgir. Es aquí que, como en otras literaturas menores que mencionamos, el inglés y el español aparecen también como formas de reafirmar esa colectividad de las literaturas menores: con este uso del lenguaje se habla a dos comunidades heterogéneas, a la comunidad angloparlante y a la comunidad hispanoparlante, pero también se crea una tercera que participa de estas dos, que puede o no conocer ambas lenguas, pero que las ha escuchado y que reconoce en ellas esos movimientos históricos que llevan a la lengua a donde está hoy, aún en esa zona liminal que puede cruzarse a pie pero que también se cruza con palabras, que también se escribe y se derrumba con poesía. A partir de esto decimos que el spanglish es border, pues aunque no aparece solamente en la frontera entre Estados Unidos y México (región ya de por sí indeterminada), está siempre atravesada por fronteras culturales en las que una lengua no dice todo lo que hay por decir, en las que se recurre a otra lengua para 
hablar de una historia que ya no se recuerda pero que se siente aún como propia, aparece ahí en esa zona liminal entre dos sistemas lingüísticos; el spanglish es border porque se encuentra siempre en una frontera simbólica entre lo anglo y lo latino, como decía Anzaldúa.

La literatura se traza como una herramienta política, como un espacio en el que es posible decir que se ha retomado un lenguaje a pesar de que su reapropiación había sido planteada como imposible. Ahí donde la gramática y la lengua se proponen como características necesarias para pensar en una lengua como tal, ahí aparece la literatura en spanglish. Quizá ahora en la literatura latina en Estados Unidos ya no aparezcan las dos lenguas tan constantemente como aparecían antes, pero los ecos de las voces que han hablado siguen resonando.

Podemos decir, entonces, que aquella necesidad por la creación de una conciencia fronteriza, una nueva conciencia mestiza, no se limita a la aparición de uno de las dos lenguas que en origen daban forma al spanglish. Es en este punto en el que nuevamente resulta inoperante hablar de sistemas lingüísticos y decir que en un enunciado aparecen ambos, o que aparece uno y no otro, o que se pasa de uno a otro, pues en cada uno de los enunciados producidos aparece esa conciencia y esta reapropiación de la lengua, aparece esa condición de hablar español fuera de los países hispanohablantes y, al mismo tiempo, la condición de hablar inglés en Estados Unidos, pero como lengua madrastra. En este último sentido, retomamos nuevamente a Derrida cuando dice "es posible ser monolingüe y hablar una lengua que no es la propia”.

La literatura en spanglish se propone entonces como una literatura que retoma lo dicho anteriormente, que retoma al inglés y al español y crea un tercer elemento, que se diferencia de lo precedente. De ahí, lo dicho en spanglish es irrupción y encuentra justamente ahí su potencia: ya no importa si se le considera lengua o no, pues aun así habla y lo hace colectivamente, pues es político.

¿Qué es, entonces, spanglish? Ya no decimos que se trata solamente de un lenguaje conformado por elementos gramaticales del inglés y del español, sino que es una posibilidad de devenir-menor, de devenir migrante en la propia lengua, de devenir-border. Ahí es donde la literatura es política, no sólo por los temas que trate, sino por la posición desde la que es creada, desde la cual se enuncia, aquella que desde las crisis migratorias, humanitarias, 
económicas y políticas, irrumpe para generar también una crisis de los conceptos lingüísticos con usos gramaticales negados por el capital lingüístico, es decir, con usos menores de dos lenguas mayores, y que encuentran en la literatura, en la escritura, un soporte para ser dichos. La literatura en spanglish, entonces, se encuentra siempre en el borde entre los sistemas lingüísticos, entre las identidades latinas, en la frontera entre be y ser.

RETOMO mi tema principal:

dibujar mapas imaginarios

crear un mapa del futuro inmediato

para que tú y yo podamos caminar sobre él

sin caer en las grandes fallas de la historia.

tú y yo, verbally walking together

you \& I, comunidad efímera

tú y yo, a tiny little nation-state

you \& I, una utopía de hora y media

titulada "you \& I"

solos en el escenario

luchando contra el Banco Mundial,

la Organización Mundial del Comercio

y el cartel de Bush

tú y yo juntitos

pero, who are you, really?

ME EMPOLVO LA CARA Y ME PONGO MI SOBRERO STETSON. PAREZCO UN CHERO GÓTICO.

Mapeando el futuro imaginario, G. Gómez-Peña $(2006,235)$ 


\section{Referencias}

Achard, Pierre. “¿La especificidad de lo escrito es de orden linguístico o discursivo?”. Hacia una teoría de la lengua escrita. Comp. Nina Catach. Barcelona: Gedisa, 1991.

Agamben, G., “Qué es un dispositivo?” en Sociológica 26, número 73 (agosto de 2011): 249-264.

Alurista. "Mis ojos hinchados". Herencia: The Anthology of Hispanic Literature of the United States. Ed. Nicolas Kanellos. Oxford: Oxford University Press, 2002.

Anzaldúa, Gloria. Borderlands/ La frontera: The New mestiza. San Francisco: Aunt Lute Books, 1987.

Ardila, Alfredo. "Spanglish: An Anglicized Spanish Dialect”. Hispanic Journal of Behavioral Sciences 27, 60 (enero 2005): 60-81. También disponible en <http://hjb.sagepub.com/content/27/1/60>

Arteaga, Alfred. An other tongue: nation and ethnicity in the linguistic borderlands. Durham:

Duke University Press, 1994.

Bajtín, M., Estética de la creación verbal. México: Siglo XXI, 1989.

Benveniste, Émile. Problemas de lingüística general (dos tomos). México: Siglo XXI, 2011.

Bloomfield, Leonard. Lenguaje. San Marcos: Universidad Nacional Mayor de San Marcos, 1964.

Borioli, Gloria. "La lengua madrastra. Identidad, territorio, pertenencia”. Educación, Lenguaje y Sociedad X, 10 (diciembre de 2013): 185-202.

Bourdieu, Pierre. ¿Qué significa hablar? Economía de los Intercambios Lingüísticos. Madrid: Akal, 2008.

Braschi, Giannina. Yo-Yo Boing! Las Vegas: Amazon Crossing, 2011.

Cardona, Giorgio Raimondo. Antropología de la escritura. Barcelona: Gedisa, 1991.

Castillo, Debra. "Chicana feminist criticism”. Latina writers. Ed. Ilan Stavans. Connecticut: Greenwood Press, 2008.

Culler, Jonathan. "Hacia una lingüística de la escritura". La Lingüística de la escritura: debate entre lengua y literatura. Madrid: Visor, 1989.

Deleuze, Gilles. El saber: curso sobre Foucault. Buenos Aires: Cactus, 2013. Dos regímenes de locos. Valencia: Pre-Textos, 2008. 
Deleuze, Gilles y Félix Guattari. Kafka, por una literatura menor. México: Era, 1990. , Mil mesetas, capitalismo y esquizofrenia. Valencia: Pre- Textos, 2002.

Derrida, Jacques. El monolingüismo del otro, o la prótesis de origen. Trad. Horacio Pons. Buenos Aires: Manantial, 1997.

Díaz, Junot. Así es como la pierdes, México: Random House Mondadori, 2012. This is How You Lose Her, New York: Penguin Group, 2012.

Fabb, Nigel y Alan Durant, "Nuevas tendencias de la lingüística de la escritura". La Lingüística de la escritura: debate entre lengua y literatura. Eds. Fabb Nigel et al. Madrid: Visor, 1989.

Forbes, Jack D. Aztecas del Norte: The Chicanos of Aztlán. California: University of California Davis, 1973.

Foucault, Michel. La arqueología del saber. México: Siglo XXI, 2017. , La gran extranjera, para pensar la literatura. México: Siglo XXI, 2015.

Franco Rodríguez, José Manuel. "El español en el condado de Miami-Dade desde su paisaje lingüístico", Lingüística en red 1, 29 (2007).

Gómez-Peña, Guillermo. Bitácora del cruce. México: Fondo de Cultura Económica, 2006.

Hernández Tovar, I. "Untitled”. La literatura chicana. Tatum Charles M. México: SEP, 1986.

Itkonen, Esa. ¿Qué es lenguaje? Introducción a la filosofía de la lingüística, Madrid: Biblioteca Nueva, 2008.

Kristeva, Julia. El lenguaje, ese desconocido: introducción a la lingüística. Madrid: Fundamentos, 1988.

Landry, R. y R. Bourhis, Linguistic Landscape and Ethnolinguistic Vitaliy: An Empirical Study. Publicado en 1997 (diciembre de 2017).

<www.academia.edu/19637508/Linguistic_Landscape_and_Ethnolinguistic_Vitality_An_E mpirical_Study >

Lara, Luis Fernando. "Para la historia lingüística del pachuco". Anuario de Letras 30 [México: Centro de lingüística hispánica, UNAM] (1992): 75-88. 
Mangelsdorf, Kate. "Spanglish as alternative discourse: working against language demarcation". Cross-language Relations in Composition. Eds. Horner et. al. Carbondale: Southern Illinois University, 2010.

Ma, Yujing. "El paisaje lingüístico chino-español de la ciudad de Valencia: una aproximación a su estudio", Lengua y migración / Language and Migration 9:1 (2017): 6384.

Morales, Ed. Living in Spanglish: the search for a new latino identity in America, New York: St. Martin, 2002.

Muzart, Thomas. "Language in risis for society in crisis? Vrigine Despentes and the case of French slang". Geolinguistic studies in language contact, conflict and development I. Ed. Wayne Finke y Hikaru Kitabayashi. North Carolina: Lulu Press, 2018.

Ong, Walter J. Oralidad y escritura: tecnologías de la palabra. México: Fondo de Cultura Económica, 1987.

Peñalosa, Fernando. Chicano sociolinguistics, a brief introduction. New York: Newbury House Publishers, 1980.

Rotaexe Amusategi, Karmele. Sociolingüística. Madrid: Síntesis, 1990.

Saussure, Ferdinand, de. Curso de Lingüística General. Buenos Aires: Losada, 1945.

Serrano, R. G., Dictionary of Pachuco terms: A Collection of Words, Phrases, Conversations and Songs as They Originally Appeared in Published Form. California: California State College, 1979.

Somoza, Oscar U. Narrativa chicana contemporánea: principios fundamentales. México: Signos, 1983.

Sonderéguer, Pedro. "Estudio del dialecto argen-mex". Lenguajes y manipulación lingüística. Lenguajes en contacto, intervenciones lingüísticas y medios de comunicación. Buenos Aires: Biblos, 2015.

Stavans, Ilan. La condición hispánica: reflexiones sobre cultura e identidad en los Estados Unidos. México: Fondo de Cultura Económica, 1999.

Stewart, A., "Un bosquejo de tipología lingüística para describir el multilingüismo". Antología de estudios de etnolingüística y sociolingüística. Mexico: UNAM, 1974.

Stewart Frankson, Marie. "Chicano Literature for Young Adults: An Annotated Bibliography”. The English Journal 79, 1 (enero 1990): 30-38. 
Tagliamonte, Sali A. Analysing Sociolinguistic Variation. Cambridge: Cambridge University Press, 2006.

Tatum, Charles M. Literatura chicana. México: SEP, 1986.

Valenzuela Arce, José Manuel. ¡A la brava ése! México: El Colegio de la Frontera Norte, 1988.

Varela, B. "Spanglish: The Making of a New American Language by Ilan Stavans (Review)", Hispania 88, 2 (mayo de 2005): 322- 323.

Winkin, Yves. "Review on L'alienation linguistique: Analyse tétraglossique by Henri Gobard”. Language in Society 9,1 (abril de 1980): 101-102.

Zeff, J., ““'What Doesn't Kill You Makes You Fat”: The Language of Food in Latina Literature". Latina Writers. Ed. Ilan Stavans. Connecticut: Greenwood Press, 2008.

Zentella, J. H., The Eve of the Macho. S/L: Heads and Tales Publishers, 1980.

\section{Consultas en internet}

Gómez-Peña, Guillermo. Brownout Pt. 2. Publicado en 2003 (mayo 2018).

< http://hempisphericinstitute.org/hemi/es/modules/item/1977-pocha-texts-brownout >

Rivera Garza, Cristina. Estar alerta: escribir en español los Estados Unidos hoy. Publicado en junio de 2018 (junio de 2018). <www.revistadelauniversidad.com>.

Rivera Cusicanqui, Silvia. La universalidad de lo ch'ixi. Miradas de waman puma. S/F (agosto 2018) < http://hemisphericinstitute.org/hemi/es/e-misferica-71/rivera-cusicanqui> .

Frohman, Denice. [Button Poetry]. (8 de abril de 2014) Borders [archivo de video] recuperado de https://www.youtube.com/watch?v=CNK7Hn5_hLQ (consultado en junio de 2017) 
[Denice Frohman]. (30 de diciembre de 2013) Accents [archivo de video] recuperado de https://www.youtube.com/watch?v=qtOXiNx4jgQ (consultado en junio de 2017)

Lozada-Oliva, Melissa. [SlamFind]. (25 de junio de 2017), "My Spanish" (en Español) [archivo de video] recuperado de http://www.youtube.com/wactch?v=sElqYWrWXLY (consultado en febrero de 2018).

[Button Poetry]. (6 de julio de 2015), "My Spanish" (WoWPS

2015) [archive de video] recuperado de http://www.youtube.com/watch?v=fE-c4Bj_RT0 (consultado en febrero de 2018).

Salgado, Yesika. [All Def Poetry]. (15 de julio de 2016) Yesika Salgado- "Translation" | All Def Poetry $x$ Da Poetry Lounge [archivo de video] recuperado de https://www.youtube.com/watch?v=P5NSNwDB_08 (consultado en junio de 2017)

Salgado, Yesika y Aman Batra. [All Def Poetry]. (21 de junio de 2016) Yesika Salgado + Aman Batra- "My Name | All Def Poetry x Da Poetry Lounge [archivo de video] recuperado de https://www.youtube.com/watch?v=seZYkCVDMO8 (consultado en junio de 2017)

Reyes, Yosimar. "TRE (My Revolutionary)". 〈http://yosimarreyes.com/poetry/> (febrero de 2018a).

"Pride". <http://yosimarreyes.com/poetry/> (mayo de 2018b). 


\section{Anexos I: poemas en spanglish}

En el presente apartado presentamos la versión completa de aquellos fragmentos de poemas en spanglish presentados a lo largo del trabajo, además de otros poemas que resultaron relevantes para la discusión aunque no hayan sido mencionados. En cada uno de los casos, especificamos los datos sobre la fuente del poema, pues algunos han sido transcritos a partir de su versión en spoken word, en video.

\section{Borders, Denice Frohman ${ }^{28}$}

It starts before she gets here

before the stairs tell her she's alien to a country that knows her great-grandfather's Mexican hands all too well

His fingerprints still echo underneath railroad tracks and cotton fields from Texas to California where bent knees and bent hands once picked, plucked, pushed, worked for more money than he was used to, but less than he deserved.

For Ana Maria, it begins before the border.

She walks with her two uncles in a desert for one week, with nothing more than a few gallons of water and a prayer tucked into their pockets hoping both will last them long enough

The Sun is an unforgiving god

But any god is worth having right now

The wind pushing at their backs, the grunt of gunshots from drug cartels and the desperation of a job to employ their stomachs

Both have been uninvited guests at their doorstep

So they step, step

Ana Maria's small hand clutches the bottom of her abuela's dress

${ }^{28}$ Transcripción del spoken word a partir de la versión en <https://www.youtube.com/watch?v=CNK7Hn5_hLQ> 
Her mother waits for her on the other side, hoping that her face still sings of home like it used to.

Another step, she is too young to know what border means

she thinks people are just family members who haven't met yet

after her family arrives she will learn there are some borders you can't cross by foot

Ana Maria is now ten years old, she's learned enough English to translate for her parents

but says that her thick accent is still a problem she tries to fix by leaving in her locker

when the teacher calls on her to read, she tries to speak "proper" like "proper" has a sound she pushes her tongue down so she doesn't roll her r's but she trips on the flatness of the syllables that bounce with too much salsa

she tries to rattle out the kinks in her speech

but her tongue is a stubborn dancer

The two boys behind her don't know how to do long division, but they know what a wetback is

And that Ana Maria has braids, and that Ana Maria's hair is thicker than their sisters

And they don't know how they know

But they know how to treat difference when they smell it, so they say things like, "YO! Go back to your country."

As if their Irish ancestors never walked through Ellis Island

Ana Maria is now 16

Her father works 18-hour days as a dishwasher

Her mother cleans houses she'll never get to live in so that Ana Maria can sit in a college classroom and say, "I am here."

But her guidance counselor says she can't get financial aid or the instate tuition rate because of her status

She says it like an apology

Ana wonders if her family ever crossed the border, or if they are just stuck inside another one, aggravating it like a soul.

Her guidance counselor stands in front of her, with a mouth full of fences.

There are some borders you can't cross by foot, but borders I tell her, that can only be crossed by stubborn backbones.

So when they ask you for your papers, Ana, show them your skin, wear your tongue like a cape,

throw up your fist like a secret you can't keep any longer, they can't keep you any longer

Afraid, you can't ever afford to drop a dream, so when they come for you, tell them, in the language that you know best

That you are not scared anymore 


\section{Accents, Denice Frohman ${ }^{29}$}

My mom holds her accent like a shotgun, with two good hands.

Her tongue, all brass knuckle

slipping in between her lips

her hips, all laughter and wind cap.

She speaks a sanchocho of Spanish and English, pushing up against one another, in rapid fire

There is no telling my mama to be "quiet", she don't know "quiet"

Her voice is one size better fit all and you best not tell her to hush, she waited too many years for her voice to arrive to be told it needed housekeeping.

English sits in her mouth remixed so "strawberry" becomes "eh-strawbeddy" and "cookie" becomes "eh-cookie" and kitchen, kay chain and chicken all sound the same

My mama doesn't say "yes"

she says "ah-ha"

and suddenly the sky in her mouth becomes a Hector Lavoe song

Her tongue can't lay itself down flat enough

for the English language, it got too much hip

too much bone

too much conga

too much cuatro

to two step

Got too many piano keys

${ }^{29}$ Transcripción a partir de la versión para spoken word, en: $<$ https://www.youtube.com/watch?v=qtOXiNx4jgQ> 
in between her teeth,

it got too much clave

too much hand clap

got too much salsa to sit still

It be an anxious child wanting to make Play-Doh out of concrete

English be too neat for her kind of wonderful

her words spill in conversation

between women whose hands are all they got

sometimes our hands are all we got

and accents remind us that we are still

bomba, still plena

Say "wepa"

and a stranger becomes your hermano

say "dale"

and a crowd becomes your family reunion

My mama's tongue is a telegram form her mother

decorated with the coqui's of el campo

So even though her lips can barely

stretch themselves around English,

her accent is a stubborn compass

always pointing her towards home

\section{TRE (My Revolutionary), Yosimar Reyes ${ }^{30}$}

You tell me you don't like the city

That these buildings, this concrete

Numbs the senses

Cages the spirit and baby

Your spirit was meant to be free

You my love

Were born to be revolutionary

\footnotetext{
${ }^{30}$ Tomado de <http://yosimarreyes.com/poetry/>
} 
Like the winds we felt sitting on top of the world

Free like the tobacco you offered me to blow blessings

Free like palabras sagradas que salen de tu boca

Y las rimas femeninas y masculinas that you bust on

stage

You are my revolutionary

Not a guerrero but a healer

Because in times of conflict

Mi rey you heal

And more then body I must agree with you that you are spirit

Because more then your flesh I am in love con el Corazon que tienes

You are the reason why I love men with noble hearts

The reason why I don't mind sharing a bed with someone

For men like you I would ride a million BARTs

Get lost in Oakland

And find your house beneath the brightest star

Mi Vida

You come from tierra

Where the spirits of those who failed to cross over roam

You come from el desierto

But baby we all know you are not deserted

You got me and together we are 4 spirits

Like the 4 directions

You got the creator behind you

you are his creation

His masterpiece

And in this journey you are traveling you have managed to leave

Your footprints in my heart

I carry your breath in my hair

Your teachings in my two spirits

You are fluid

Como los Rios que nuestra gente a cruzado

You remind me that the only possessions we have in this world

Are our bodies and our voice

And the combination of the two must be used

To honor the spirits oflos antepasados

This life is a ritual

And in its sacredness

I am so glad that I am able to hug you

You are my revolutionary...

And as you make your transition back home

Into the arms of your mother 
Into the lips of your father

I ask that you take this poem with you

Take a memory of me with you

Plant these

En la tierra que te vio nacer

En esa tierra que hacido bautizada

Con la sangre sagrada de nuestra gente

And I will assure you

that where ever you be

This love will sprout a new

Como el sol por las mananas this poem will shine on you.

Now go

to where ever home is

Knowing that in San Jose

You leave a brown boy

That has nothing but love and respect for you.

In the mean time,

I will stay here

in this cage, in this shitty city

Singing and singing

Till this system crumbles

Till borders break

Till the earth shakes

And our people become awake

I will be here

Singing and singing till the day

We are all free to return

HOME

\section{Pride, Yosimar Reyes ${ }^{31}$}

I am more than body

Beyond the rainbow flags and free condoms

The celebration of me is not found in parades

${ }^{31}$ Recuperado de <http://yosimarreyes.com/poetry/> 
In a sea of half-naked men dancing to techno

The celebration for my spirit

Is not found in wet underwear contests

Random hook-ups

Over-sexualized drama

Or STDs

More than Dick I often think of spirit

And the fact that I've been broken

Through systems that keep me blind to my own self-actualization

Prevent me from seeing that I am Two-Spirit

Como sacred ceremonias

Mi cuerpo es elemento

Something powerful

Algo that goes beyond the flesh

And is manifested through these poems

I am not Gay

Yo soy voz del más allá

Bendición de Ometeolt

Las dos energías

Something that cannot be described through a simple three- Letter word Like GAY

My sexuality does not define me

It is a simple intersection of my being

Because more then body, I am a complex identity

I am of energías flowing like rivers

Movements of our people pimping a system

Yo soy piel de tambores creando ritmos de corazones

This is who we are

No cuerpo solo espíritu

Voices of people not celebrated

In white capitalistic wannabe inclusive parades of individuals

Nosotros somos Two- Spirit

And their pride is not ours

Because as they celebrate pop stars 
And liberate their bodies

We are still caged

In their system

Still silent

Not speaking about spirituality

And that fact that we need

A sacred space

To share Intersectionality

We need espacios

In which the focus is not getting laid

But empowering our spirits

Arming ourselves

With the truth

that we all must heal

Move pass this fake notion that we are liberated individuals

And finally state

That we are caged creatures

\section{My Name, Yesika Salgado y Aman Batra ${ }^{32}$}

I'm six years old and speak fluent Punjabi

I'm six years old correcting my mother's English

I'm ten years old ironing mommy out my tongue and hair

I'm ten years old wishing Lauralie Gilmore would be my mother

At eleven I make a speech of how to properly pronounce my name in front of my fifth grade class

It's Aman

Afterwards, a boy comes up to me and says:

"I'm just gonna call you Aman"

I say: "sorry, go ahead"

My name is now a full on apology

Go to Bollywood dance and no one knows the choreography

At thirteen I'm on the phone with a boy I've never met

I tell him my name is Yesika

He asks me if I'm white and I almost say yes

32 Transcripción a partir del spoken word en <https://www.youtube.com/watch?v=seZYkCVDMO8> 
I'd watched the Yesika's of my world wrap their white swan wings while we are around the same boys who could not stomach the whole of me

We are at a middle school dance and I'm not sure who I hate more,

Them, or myself

The loathing wraps around my neck like a fist scarf in a hot room

This is when I learned to associate being brown with suffocation

Whiteness, with desire

When you're an American brown girl with two languages growing inside of you, you ask

yourself hoy your name fits into a world that doesn't call you how your dead father used to call you

Yesika mi corazón

Aman [Punjabi]

Yesika mi amor

Aman [Punjabi]

Yesika mi vida

Aman [Punjabi]

You wonder what is a name if it isn't a thrown knife cutting a hole into you

At twenty three I changed the spelling of my name to look like Ed Salvador

Yesika sound more like me, a brown girl with an accent she can't shake

I introduce myself to a white woman

Yesika like Jessica?

No, it's Yesika, I repeat

Most days I don't even correct people when they mispronounce my name

I always think their tongues are at the same place as their hearts

I get accused to be too complicated when I ask for someone to say my whole name, every syllable of it,

As if I should apologize for the work that it takes

But why?

When my name is the only thing that's been given to me

without the expectation of something in return

If we can go to every conversation speaking Spanish

Or Punjabi

[ininteligible]

Yo me llamo Yesika

[Punjabi] Aman

My name is all I have to call my own

Say it right,

or don't say it at all. 


\section{Transaltion, Yesika Salgado ${ }^{33}$}

I do most of my writing in English.

Papi never like this speaking in Spanglish.

If you ever heard us sputtering in either language

from across the room you would yell: "spit it out".

But sometimes at home, I'll put on my Spanish

and it'll feel like I'm wearing my mother's wedding dress

but Mommy didn't marry in a church,

Mommy didn't have a big pretty gown,

instead what she wore was a two-piece suit,

married in an office somewhere, my sisters and I

were the witnesses and we ate at a pupusería nearby

before heading home.

This is Spanish for me, everything that should be,

but quite isn't, it's like coming home,

but all the furniture is different.

Then there's English and everything is painted in its color.

Think of that gray that settles in and around dusk,

that is English. Sometimes I get lost in it and then

the shape of words, what they feel and look like

when I go to reach for one, I somehow mess it all up.

I laughed, turned bright in the face I blamed the

Spanish, it came first, it is home.

Papi would drink, and after drinking he

would talk. He often chose English

with a brown, crumpled bag and I'd yell: "háblame en español, Papi"

But he would refuse. It was usually a lecture

you see formal things in my home only came

in English but whenever he was happy, he would

call me to him: "ven aquí, corazón"

and I would go.

Papi was papi or apa or abuelo

sometimes even papa,

but never father. I save that for the poems about

his drinking, about my angry hurt,

about how far away it pushed me,

I don't write

about that in Spanish.

Things are too real in that language

${ }^{33}$ Transcripción a partir del spoken word en 〈https://www.youtube.com/watch?v=P5NSNwDB_08> 
so I keep it for love songs.

For my boys who have no idea what I'm saying

but they think it sounds beautiful, right?

I say things like mi vida, mi cielo, mi amor, mi rey, mi tesoro

my fingers and my hair, and the head on my lap

and of talking and

talking and saying all those pretty things,

my mother used to pour over me when I was still

small enough to be held.

So, that's what I'm

saying is that Spanish is a feeling, a squeeze, an ache, a corner of myself, I can't seem to

quite get to, an English word isn't so much of a feeling but an action, a dance that I know all the steps too, but still feel awkward dancing.

Una vez, cuando tenía dieciéis años, me enamoré de un muchacho

y él habla mis dos idiomas

pero la primera vez que me besó yo entendí de que aunque yo piense en inglés

mi cuerpo, mi cuerpo responde en español

Y mi Papi siempre me dijo: "un idioma a la vez"

$Y$ así me la he pasado, cambiando de idioma como que si fueran zapatos

un par a la vez.

I am always wearing one language at a time and

I will spend the rest of my life trying to

learn about everything I lost, we lost in

translation.

\section{Mi español, Melissa Lozada-Oliva ${ }^{34}$}

Si me preguntas qué tan fluido es mi español yo te diré:

mi español es la comezón de un brazo amputado:

busca palabras y sólo encuentra aire

Mi español es mi tercera fiesta de cumpleaños:

la mitad la tengo en mi memoria, la otra mitad es una fotografía en el refrigerador, es lo que mi familia me ha dicho

Si me preguntas si mi español es fluido,

${ }^{34}$ Transcripción a partir del spoken word en $\langle$ https://www.youtube.com/watch?v=V8pyXEBj0CA> 
te diré que mi español es un rompecabezas olvidado bajo la lluvia:

muy mojado como para hacer que sus piezas embonen y entonces sea igual a la foto de la caja

Te diré: mi español son adjetivos posesivos,

Son nombres propios que visten en perlas y brazaletes

Es el ¿sigues despierto?

Es el hay mucho que hacer hoy

Mi español está en mi currículum como una habilidad

Mi español está en mi cepillo de dientes como una marca roja de mis labios

Si me preguntas te diré que mi español tiene más hambre que antes

Mi español busca palabras que están encima de los anaqueles sin usar una escalera,

es golpeado en la cabeza por todas esas antiguas palabras que han estado ocultas ahí arriba

Mi español se pregunta qué tan malo será comer algo que expiró

Mi español se pregunta si acaso él tiene fecha de expiración

Si me preguntas qué tan fluido es mi español,

te diré que mi español

muerde un lápiz en la esquina del salón de clases y no alza la mano

Mi español es la dolida sonrisa de mi hermana mayor

en su único desfile de belleza

Mi español es una historia inventada sobre un padre

que jamás volvió a casa y viajó por hermosos lugares

y me mandó postales de todos ellos

Mi español soy yo, calcando mis dedos en cada letra donde pueden caber

Mi español es la verdadera historia del divorcio de mis padres,

caótico, roto y otra cosa que tuve que elegir para recordarlo correctamente

Mi español se pregunta cuándo mis padres serán ciudadanos americanos

que me pregunten si aún soy blanca

Si me preguntas qué tan fluido es mi español,

te contaré la historia de cómo mis padres se conocieron en la clase de inglés,

cuando entrenaban sus bocas para decir "te amo" en un idioma diferente ,

"te odio" con la boca cerrada

Te diré cómo el acento de mi padre lo hace sonar como zoro

cómo mi madre intentó amarrar su lengua a un poste con la cadena del idioma inglés

Te diré que su lengua siempre volvía terca

hacia el idioma del que siempre estuvo enamorada, 
incluso cuando quería tomarla, siempre volvía

Si me preguntas si fluyo te diré que mi español es el comprender que hay historias que siempre estarán fuera de mi alcance, que hay personas que nunca embonarán entre ellas de la manera en la que a mí gustaría (sic) Hay letras que siempre permanecen calladas

Hay algunas palabras que siempre se me van de las manos

\section{My spanish, Melissa Lozada-Oliva ${ }^{35}$}

If you ask me if I am fluent in Spanish I will tell you

My Spanish is an itchy phantom limb: reaching for a word and only finding air

My Spanish is my third birthday party: half of it is memory, and the other half is a photograph on the fridge is what my family has told me

If you ask me if I am fluent I I will tell you that

My Spanish is puzzle left in the rain

Too soggy to make its parts fit so that it can look just like the picture on the box.

I will tell you that

My Spanish is possessive adjectives.

It is proper nouns dressed in pearls and bracelets.

It is are you up yet. It is there is a lot to do today

My Spanish is on my resume as a skill.

My Spanish is on a toothbrush in red-mouth marks

If you ask me I will tell you

My Spanish is hungrier than it was before.

My Spanish reaches for words at the top of a shelf without a stepping stool is hit in the head with all of the old words that have been hiding up there

My Spanish wonders how bad is it to eat something that's expired

My Spanish wonders if it has an expiration date

My Spanish asks you why it is always being compared to food spicy, hot, sizzle

my Spanish tells you it is not something to be eaten

\footnotetext{
${ }^{35}$ Recuperado de <https://www.youtube.com/watch?v=fE-c4Bj_RT0\&t=8s >
} 
but does not really believe it.

If you ask me if I am fluent in Spanish I will tell you that

My Spanish bites on a pencil in the corner of a classroom and does not raise its hand

My Spanish is my older sister's sore smile at her only beauty pageant

My Spanish is made up story about a parent who never came home

My Spanish is made up story about a parent who never came home and traveled to beautiful places and sent me post cards from all of them

My Spanish is me, tracing my fingers along every letter they were able to fit in

My Spanish is the real story of my parent's divorce

Chaotic, broken and something I have to choose to remember correctly

My Spanish is wondering when my parents will be American

asking me if I'm white yet

If you ask me if I am fluent in Spanish I will try to tell you the story

of how my parents met in an ESL class

How it was when they trained their mouths to say

I love you in a different language, I hate you with their mouths shut

I will tell you how my father's accent makes him sound like Zoro

how my mother tried to tie her tongue to a post with an English language leash

I will tell you that the tongue always ran stubbornly back to the language it had always

been in love with

Even when she tried to tame it it always turned loose

If you ask me if I am in fluent

I will tell you

My Spanish is understanding that there are stories will always be out of my reach

there are people who will never fit together the way that $i$ want them to

there are letters that will always stay silent

there are some words that will always escape me.

\section{To live in the borderlands, Gloria Anzaldúa ${ }^{36}$}

To live in the borderlands means you

are neither hispana india negra espanola

ni gabacha, eres mestiza, mulata, half-breed

\footnotetext{
${ }^{36}$ Tomado de Anzaldúa, Gloria. Borderlands/ La Frontera: The New Mestiza. San Francisco: Aunt Lute Books, 1987.
} 
caught in the crossfire between camps

while carrying all five races on your back

not knowing which side to turn to, run from;

To live in the Borderlands means knowing that the india in you, betrayed for 500 years, is no longer speaking to you,

the mexicanas call you rajetas, that denying the Anglo inside you

is as bad as having denied the Indian or Black;

Cuando vives en la frontera

people walk through you, the wind steals your voice,

you're a burra, buey, scapegoat,

forerunner of a new race,

half and half-both woman and man, neither-a new gender;

To live in the Borderlands means to

put chile in the borscht,

eat whole wheat tortillas,

speak Tex-Mex with a Brooklyn accent;

be stopped by la migra at the border checkpoints;

Living in the Borderlands means you fight hard to

resist the gold elixir beckoning from the bottle,

the pull of the gun barrel,

the rope crushing the hollow of your throat;

In the Borderlands

you are the battleground

where enemies are kin to each other;

you are at home, a stranger,

the border disputes have been settled

the volley of shots have scattered the truce

you are wounded, lost in action

dead, fighting back;

To live in the Borderlands means

the mill with the razor white teeth wants to shred off

your olive-red skin, crush out the kernel, your heart

pound you pinch you roll you out

smelling like white bread but dead;

To survive the Borderlands

you must live sin fronteras

be a crossroads. 


\section{El otro México, Gloria Anzaldúa ${ }^{37}$}

Wind tugging at my sleeve

feet sinking into the sand

I stand at the edge where earth touches ocean

where the two overlap

a gentle coming together

at othe rtimes and places a violent clash.

Across the border in Mexico

stark silhouette of houses gutted by waves,

cliffs crumbling into the sea,

silver waves marbled with spume

gashing a hole under the border fence.

Miro el mar atacar

la cerca en Border Field Park

con sus buchones de agua

an Easter Sunday resurrection

of the brown blood in my veins.

Oigo el llorido del mar, el respire del aire,

my heart surges to the beat of the sea.

in the gray haze of the sun

the gulls' shrill cry of hunger,

the tangy smell of the sea seeping into me.

I walk through the hole in the fence

to the other side.

Under my fingers I feel the gritty wire

rusted by 139 years

of the salty breath of the sea.

Beneath the iron sky

Beneath the iron sky

Mexican children kick their soccer ball across, run after it, entering the U.S.

I press my hand to the steel curtain-

chainlink fence crowded with rolled barbed wire-

rippling from the sea where Tijuana touches San Diego

unrolling over mountains

and plains

and deserts,

this "Tortilla curtain" turning into el río Grande

${ }^{37}$ Tomado de Anzaldúa, Gloria. Borderlands/ La Frontera: The New Mestiza. San Francisco: Aunt Lute Books, 1987. 
flowing down to the flatlands

of the Magic Valley of South Texas

its mouth emptying into the Gulf.

1,950 mile-long open wound

dividing a pueblo, a culture

running down the length of my body,

staking fence rods in my flesh,

splits me splits me

me raja me raja

This is my home

this thin edge of

barbwire.

But the skin of the earth is seamless.

The sea cannot be fenced,

el mar does not stop at the borders.

To show the white man what she thought of his

arrogance,

Yemayá blew that wire fence down.

This land was Mexican once,

was Indian always

and is.

And will be again.

Yo soy un puente tendido

del mundo gabacho al del mojado,

lo pasado me estira pa 'trás

y lo presente pa' delante,

Que la Virgen de Guadalupe me cuide

Ay ay ay, soy mexicana de este lado

\section{Brownout Pt. 2, Guillermo Gómez-Peña ${ }^{38}$}

Minimum requirements include a table covered with a black cloth for props, capability to isolate the performance area with lights. Two high-quality mics (one cordless), sound equipment to reproduce CDs, a video projector connected to a video disc console, and two technicians (sound \& lights/video). Minimum 4 hours prior to the event to prepare the space, and a dressing room with soft-light, big mirrors, and good espresso.

${ }^{38}$ Tomado de <http://hemisphericinstitute.org/hemi/es/modules/item/1977-pocha-textsbrownout> 
Optional: a motorized wheel-chair, and an spx-sound effect machine. Props/costumes to bring: Complete attire of "Travelling Medicine Vato" and/or S\&M Zorro. Besides, I need to bring glasses with blinders, techno-glasses, rubber heart, robo-hand, bandana, stetson hat, make-up brush, Spanish dagger, wrestler mask, and scissors. Props to be obtained by space: battery-operated megaphone, hospital mask, realisticlooking handgun, Mr. Clean bottle filled with blue Gatorade, deodorant spray can, and a bottle of Meyers rum.

(If I have more than two days to rehearse in the space, and there is a decent budget, I could bring another collaborator with me and/or incorporate a local DJ, an opera singer and/or cellist, preferably people with performative personalities willing to experiment and try out my "ethno-techno" costumes.)

INTRO BY ELAINE KATZENBERGER(UPON REQUEST)

(Insert for the program)

Border blessing:

Norte:

Dear son, my only candle left,

I promise I'll protect you from those norteño gangs.

Remember: I am analog-you told me

Which means, I still know how to use my fists...\& my legs.

Sur:

Dear mother, my historical womb \& genetic code,

I promise I will clean up my act before I die

Clean up my house de paso.

Carolina, mon amour, I promise I'll be beside you

Catering to your most minute desires

Licking your knees \& palms

Until globalization derails

\& Popocatepetl ceases to smoke.

Oeste:

Dear clica, familia espiritual, I ask for your forgiveness.

My absence was clearly a survival strategy.

How else was I supposed to outlive the backlash, the INS, the IRS \& the formalist art critics?

How else was I supposed to finish this script?

Dear criminals, pochos, locas y destrampados

"Life without you all, my nomadic tribe, is virtual horror vacui en gringolandia."

These words are for you, about you.

My job tonight is to shatter the world

With the word, my only weapon left.

Am I delusional carnales?

I WALK ON STAGE \& POSITION MYSELF BEHIND THE TABLE WHERE MY 
PROPS LIE; I BLESS

THE SPACE WITH "SACRED SPRAY" THEN I DRINK FROM MR. CLEAN BOTTLE $\&$ SPIT OUT

Intro.

Dear audience:

Tonight from my multiple repertoires of hybrid personas,

I have chosen to come as

the embodied psyche of an existentialist mojado

\& it's quite a challenge my dear friends

for I've been stripped by airport security

of all my robo-baroque paraphernalia

my ethno-technobilia ye-ye

which means,

no more hand-made lowrider prosthetics

no mariachi robotic bodywear

no cheesey fog machines

no hanging dead chickens, nothing

not even a voice-effect processor

to help me get rid of my accent

just one costume,

\& a bit of make-up

to protect myself

o sea, back to the basics of performance

It's Chicano minimalism

a contradiction in terms

but hell, I am a walking contradiction

$\&$ so are you...

So, dear foreign audience:

Welcome to my conceptual set

Welcome to my performance universe

Welcome to my delirious psyche

Welcome to my borderzone

to the cities and jungles of my language

las del ingles y las del español

kick back,

light up your conceptual cigarette...

a prop

I LIGHT UP A CIGARETTE \& INHALE

$\&$ breathe in, breathe out,

breathe in, breathe out

rreelllaaaxxxx

now, reach over,

grab the crotch of your neighbor

$\&$ massage

yes...

this is the basic exercise of Chicano Tantra

I SNAP MY FINGERS 


\section{Anexos II: cronología de literatura en spanglish}

A partir de la lista de obras de autores mexicanos y de origen mexicano que Oscar U. Somoza expone en Narrativa chicana contemporánea: principios fundamentales $(1983)^{39}$, donde retoma obras desde 1854 hasta 1980, presentamos ahora una breve cronología de literatura latina escrita en Estados Unidos, en spanglish, publicada hasta 2018. Para esto también retomamos el trabajo de Marie Stewart Frankson, Chicano Literature for Young Adults: An Annotated Bibliography $(1990)^{40}$.

1854- A. A. Orihuela, Un cadáver sobre el trono

1865- J. M. Ramírez, Celeste

Ella y nosotros

1892- Eusebio Chacón, El hijo de la tempestad

Tras la tormenta la calma

1915- Mariano Azuela, Los de abajo

1935- Teodoro Torres, La patria perdida

1940- Fray Angélico Chávez, New Mexico Tryptych

1947- Josephina Niggli, Step Down Elder Brother

1954- Fray Angélico Chávez, La conquistadora

1959- José Antonio Villarreal, Pocho

1963- John Rechy, City of Night

1967- John Rechy, Numbers

Floyd Salas, Tatoo (sic) the Wicked Cross

1969- Raymondo Barrio, The Plum Plum Pickers

Floyd Salas, What Now My Love

John Rechy, This Day's Death

1970- Richard Vásquez, Chicano

1971- Tomás Rivera, ... y no se lo tragó la tierra

Sabine R. Ulibarrí, Tierra amarilla (cuentos)

${ }^{39}$ Somoza, Oscar U. Narrativa chicana contemporánea: principios fundamentales. México D. F.: Signos, 1983.

40 Stewart Frankson, Marie. "Chicano Literature for Young Adults: An Annotated Bibliography”. The English Journal 79, 1 (enero 1990): 30-38. 
Arthur Tenorio, Blessing From Above

John Rechy, The Vampires

Ernesto Galarza, Barrio Boy

1972- Rudolfo Anaya, Bless me, Ultima

John Rechy, The Fourth Angel

Oscar Z. Acosta, The Autobiography of a Brown Buffalo

Rogelio Leonardo Carpintero, Las desventuras de un chicano

1973- Rolando Hinojosa, Estampas del Valle

José Acosta Torres, Cachito mío

Edmundo Villaseñor, Macho

J. L. Navarro, Blue Day on Main Street (cuentos)

Oscar Z. Acosta, The Revolt of the Cockroach People

1974- Miguel Méndez M., Peregrinos de Aztlán

Armando Rafael Rodríguez, editor, The Gypsy Wagon: un sancocho de cuentos

sobre la experiencia chicana

Robert C. Medina, Two Ranges

José Antonio Villarreal, The Fifht Horseman

1975- Alejandro Morales, Caras viejas y vino Nuevo

Ron Arias, The Road to Tamazunchale

Estela Portillo, Rain of Scorpions (cuentos)

Berta Ornelas, Come Down From the Mound

1976- Rolando Hinojosa, Klail City y sus alrededores

Rudolfo Anaya, Heart of Aztlán

Orlando Romero, Nambé- Year One

Aristeo Brito, El diablo en Texas

Isabel Ríos, Victuum

Joseph Torres- Metzgar, Below the Summit

1977- Rolando Hinojosa, Generaciones y semblanzas (versión bilingüe de Klail City y sus

alrededores)

Saúl Sánchez, Hay plesha lichans tu di flac

Arturo Rocha Alvarado, Crónica de Aztlán: a Migrant's Tale 
Nash Candelaria, Memories of the Alhambra

John Rechy The Sexual Outlaw

Sabine Ulibarrí, Mi abuela fumaba puros (cuentos)

1978- Floyd Salas, Lay my Boyd on the Lie

Robert C. Medina, Fabián no se muere

Tomás Sánchez, Zoot-Suit Murders

Richard Vásquez, The Giant Killer

1979- Rudolfo A. Anaya, Tortuga

Alejandro Morales, La verdad sin voz

John Rechy, Rushes

Tomás Sánchez, Rabbit Boss

Miguel Méndez M., Cuentos para niños traviesos

Luis Valdez, Zoot Suit

1980- Sergio Elizondo, Rosa la flauta (cuentos)

Rudolfo Anaya, editor, Cuentos chicanos

Miguel Méndez M., Tata Casehua y otros cuentos

1981- Gloria Anzaldúa, This Bridge Called My Back: Writings by Radical Women of Color

Lorna Dee Cervantes, Emplumada

José Antonio Burciaga, Versos para Centroamérica

I Remember Masa

1983- Cherríe Moraga, Loving in the War Years: lo que nunca pasó por sus labios

Cherríe Moraga, editora, Cuentos: Stories By Latinas

1984- Sandra Cisneros, The House on Mango Street

1985- Margarita Cota-Cárdenas, A Chicano Novella

1986- Ana Castillo, The Mixquiahuala Letters

1987- Gloria Anzaldúa, Borderlands/ La Frontera

1990- Ana Castillo, Sapogonia: An anti-romance in 3/8 meter

1991- Gloria Anzaldúa, Prietita Has a Friend

Julia Alvarez, How the Garcia Girls Lost Their Accents

1993- Guillermo Gómez- Peña, Warriors of Gringostroika

1996- Junot Díaz, Drown 
1998- Giannina Braschi, Yo-Yo Boing!

2000- Edmundo Paz Soldán y Alberto Fuguet, Se habla español: voces latinas en USA

Pam Muñoz Ryan, Esperanza Rising

2002- Sandra Cisneros, Caramelo

2005- Salvador Plascencia, The People of Paper

2006- Guillermo Gómez-Peña, Bitácora del cruce

Ángel Lozada, No quiero quedarme sola y vacía

2007- Junot Díaz, The Brief Wondrous Life of Oscar Wao

Alicia Gaspar de Alba, Calligraphy of the Witch

Daniel Alarcón, Lost City Radio

2008- Matt de la Peña, Mexican WhiteBoy

Emanuel Xavier, editor, Mariposas: A Modern Anthology of Queer Latino Poetry

2009- Yosimar Reyes, For Colored Boys Who Speak Softly

2011- Justin Torres, We the Animals

2012- Junot Díaz, This is How You Lose Her

2016- Yosimar Reyes, Prieto

2017- Melissa Lozada-Oliva, Peluda

Yesika Salgado, Corazón

2018- Yesika Salgado, Tesoro

Christopher Soto, editor, Nepantla: An Anthology Dedicated to Queer Poets of Color 
LAS ESCRITURAS DE SPANGLISH EN EL SIGLO XXI.
En la Ciudad de Mexico, se presentaron a las 11:00 horas del dia 14 del mes de enero del ano 2019 en la Unidad Iztapalapa de la Universidad Autonoma Metropolitana, los suscritos miembros del jurado:

DRA. LAURA ADRIANA HERNANDEZ MARTINEZ MTRO. JUAN CRUZ CUAMBA HERREJON

DRA. BLENA SLOVENIA MARTINEZ TREVIÑO
Bajo la Presidencia de la primera y con caracter/de Secretaria la última, se reunieron para proceder al Examen de Grado cuya denominación aparece al margen, para la obtención del grado de:

MAESTRA EN HUMANIDADES (LINGUISTICA) DE: JESSICA DEL CARMEN CONTRERAS MENDEZ

y de acuerdo con el articulo 78 fracción III del Reglamento de Estudios Superiores de la Universidad Autonoma Metropolitana, los miembros del jurado

resolvieron:

JEŚSICA DEL CARMEN CONTRERAS MENDEZ Z: $:$ ALUMNA

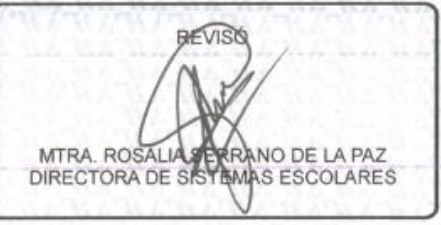



Acto continuo, la presidenta del jurado comunicó a la interesada el resultado de la evaluación $y$, en caso aprobatorio, le fue tomada la protesta.

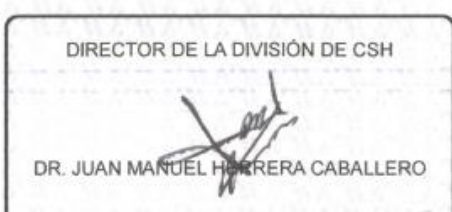

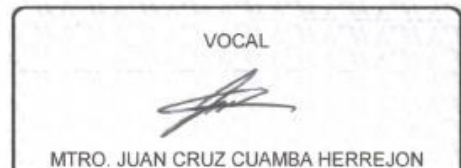

MTRO. JUAN CRUZ CUAMBA HERREJON
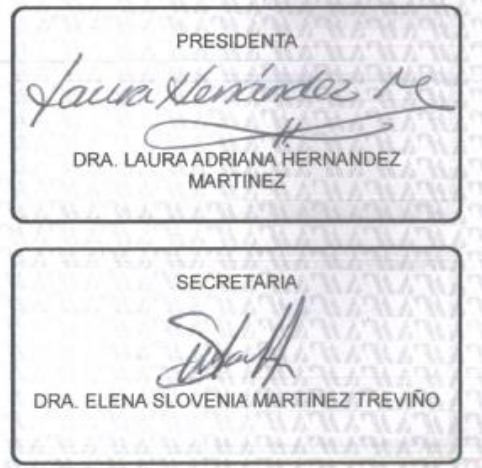